US Army Corps

of Engineers $s_{\circledast}$

Engineer Research and

Development Center

Integrating Systems Thinking Skills with MultiCriteria Decision-Making Technology to Recruit Employee Candidates

Sofia Karam, Morteza Nagahi, Vidanelage L. Dayarathna

June 2021

(Nick), Junfeng Ma, Raed Jaradat, and Michael Hamilton 
The U.S. Army Engineer Research and Development Center (ERDC) solves the nation's toughest engineering and environmental challenges. ERDC develops innovative solutions in civil and military engineering, geospatial sciences, water resources, and environmental sciences for the Army, the Department of Defense, civilian agencies, and our nation's public good. Find out more at www.erdc.usace.army.mil.

To search for other technical reports published by ERDC, visit the ERDC online library at https://erdclibrary.on.worldcat.org/discovery. 


\section{Integrating Systems Thinking Skills with Multi- Criteria Decision-Making Technology to Recruit Employee Candidates}

Sofia Karam, Morteza Nagahi, Vidanelage L. Dayarathna, Junfeng Ma, Raed Jaradat

Department of Industrial and Systems Engineering

Mississippi State University

Starkville, MS 39762

Michael Hamilton

Institute for Systems Engineering

Mississippi State University

Starkville, MS 39762

Final report

Approved for public release; distribution is unlimited.

Prepared for U.S. Army Corps of Engineers

Washington, DC 20314

Under Program Element 0603461A, Project Number DW5, Task Number 01 


\section{Preface}

This study was conducted for the U.S. Army Corps of Engineers (USACE) Engineer Research and Development Center (ERDC) under Program Element 0603461A, Project Number DW5, and Task Number 01 for the DoD High Performance Computing Modernization Program (HPCMP). The technical monitors were Dr. Simon R. Goerger and Dr. Randy K. Buchanan.

The work was performed by the Department of Industrial and Systems Engineering and Institute for Systems Engineering at Mississippi State University. At the time of publication of this Miscellaneous Paper, Dr. Simon R. Goerger was ITL Institute for Systems Engineering Research (ISER) Director; Dr. Jerry Ballard was ITL Computational Science and Engineering Division Chief; and Dr. Robert Wallace was the ERDC-ITL Technical Director for Engineered Resilient Systems. The Deputy Director of ERDC-ITL was Ms. Patti Duett, and the Director of ERDC-ITL was Dr. David Horner.

This paper was originally published online in Expert Systems with Applications on 30 May 2020. Project funding was under Army RDTE.

The Commander of ERDC was COL Teresa A. Schlosser and the Director was Dr. David W. Pittman.

DISCLAIMER: The contents of this report are not to be used for advertising, publication, or promotional purposes. Citation of trade names does not constitute an official endorsement or approval of the use of such commercial products. All product names and trademarks cited are the property of their respective owners. The findings of this report are not to be construed as an official Department of the Army position unless so designated by other authorized documents. 


\title{
Integrating Systems Thinking Skills with Multi-Criteria Decision-Making Technology to Recruit Employee Candidates
}

\begin{abstract}
The emergence of modern complex systems is often exacerbated by a proliferation of information and complication of technologies. Because current complex systems challenges can limit an organization's ability to efficiently handle socio-technical systems, it is essential to provide methods and techniques that count on individuals' systems skills. When selecting future employees, companies must constantly refresh their recruitment methods in order to find capable candidates with the required level of systemic skills who are better fit for their organization's requirements and objectives. The purpose of this study is to use systems thinking skills as a supplemental selection tool when recruiting prospective employees. To the best of our knowledge, there is no prior research that studied the use of systems thinking skills for recruiting purposes. The proposed framework offers an established tool to HRM professionals for assessing and screening of prospective employees of an organization based on their level of systems thinking skills while controlling uncertainties of complex decision-making environment with the fuzzy linguistic approach. This framework works as an expert system to find the most appropriate candidate for the organization to enhance the human capital for the organization. Several large industries, among others, Boeing, the government such as the Army, Military Academy, and National Science Foundation, highlighted the significance of having qualified (systemic) individuals who can successfully deal with complex systems problems. The correct recruiting decision will reduce the rate of job turnover and also help organizations to eliminate unnecessary budget allocated for costly recruitment processes. The proposed framework is intended to first evaluate the pool of applicants according to their level of systems thinking skills and then rank them based on the recruitment strategy and workforce needs of the organization. To achieve the purpose of the study, two recruiting strategies are adopted from the human resource management literature 1) Job-Fit Recruiting strategyfinding candidates who are most aligned with a specific position requirement and 2) Flexible Recruiting strategy - finding candidates with the highest potentials. The proposed framework is validated using a real case study in a US large-scale organization.
\end{abstract}




\section{Introduction}

A successful organization must have in place an effective system of recruitment in order to hire the best candidates for particular positions (Leisink \& Steijn, 2009). The organization's recruitment system is essential, and as Ahmad and Schroeder (2002) stated, "paying close attention to recruitment and selection is consistent with one of the basic principles of quality management, which is the notion that prevention is better than a cure. It is hard to modify (cure) negative behavioral traits of employees. Therefore, it is best to check for requisite behavioral traits during the recruitment and selection process to prevent a mismatch between the technical and social systems". An organization with "staff [employees] who consistently fulfill their roles and are capable of taking on increased responsibilities," has a competitive advantage over their rivals when dealing with complex system problem domains (Cole, 2002, p. 172). Employees' attributes, including ability and motivation, shape the organization's performance and should be considered in the recruitment process (Delery \& Shaw, 2001). Among the skills a high-quality employee should have is the ability to engage in turbulent and complex environments; this ability is referred to as systems thinking (Checkland, 1999; Schiuma, Carlucci \& Sole, 2012). Systems thinking is the thought process that promotes thinking and speaking in a new holistic language (Checkland, 1999).

A report "Future of Jobs" published by World Economic Forum in 2016, surveyed strategic leaders and upper management of top 100 companies of nine major industries, including basic and infrastructure, consumer, energy, financial services and investors, healthcare, information and communication technology, media, entertainment and information, mobility, and professional services in 15 major developed and emerging economic countries to find employment, skills, and workforce strategies needed for the fourth industrial revolution. The report discussed complex problem solving and systems skills as important skills for the next five years, outpacing the need for other skills such as people management, emotional intelligence, content skills, etc. Similarly, several large industries, among others, Boeing, the government such as the Army, Military Academy, and National Science Foundation, highlighted the significance of having qualified individuals who can successfully deal with complex systems problems. In the literature, systems thinking plays a significant role by providing tools and techniques to solve complex systems problems (Boardman \& Sauser, 2006; DeLaurentis, 2005; Gorod, Sauser, \& Boardman, 2008; Hossain et al., 2020; Jaradat et al., 2018). However, the performance of existing tools and techniques are limited by their design and integrity to facilitate comprehensive solutions for social-technical problems. For instance, many of the existing tools focus on specific domains such as education to assess students' systems thinking skills (Camelia \& Ferris, 2016; Frank, 2002; 2010). Also, some other tools have limited capabilities as they evaluate one or few aspects of systems thinking (Dolansky \& Moore, 2013; Hopper \& Stave, 2008; Plate, 2008). In this study, researchers used a comprehensive tool (Jaradat, 2015), which consists of seven 
dimensions of systems thinking skills as selection criteria to find systems thinkers based on the organizational job requirements. The proposed selection criteria will reshape the traditional recruiting process by assisting organizations in determining individuals who can work in the complex systems problem domain.

Over the past decade, the person-job fit has been a trending topic in the industry because of the high turnover and the cost of employing new staff (Hoffman \& Woehr, 2006; Liu et al., 2010). Many studies have emphasized the advantages of matching Individuals' skills with job requirements as it decreases the likelihood of job resignations (Dahling \& Librizzi, 2015; Hesketh, 1993; Schneider et al., 1995). Thus, it is important to compare an individual's skillset with the degree of work complexity in an organization while examining the other qualifications in the recruitment process. The proposed recruitment framework investigates the individuals' capability of dealing with complex system problems using seven dimensions (level of Complexity, Autonomy, Interaction, Uncertainty, Change, Hierarchical View, and Flexibility). Through the broad spectrum of determining individuals' systems thinking skills, this study assists recruiters in finding the right candidate to fit the posted job position based on the candidate's skill set.

Employees are challenged to maintain and elevate their performance during periods of increasing complexities and pressures due to factors such as a reduction in workforce, resources, and costs. These challenges include high levels of 1) complexity - large scale systems with a high flow of information, technical, and contextual issues; 2) integration - systems combined operationally, managerially, or geographically to produce new goals; 3 ) interdependence - mutual influence among systems and their related elements, making analysis difficult; 4) evolutionary development - issues related to technological changes, the evolution of requirements, and evolution of the social infrastructure because of the interaction with the surrounding environment; 5) uncertainty - incomplete knowledge of systems and the unintended consequences they experience; 6) hierarchical view - compatibility among multiple perspectives and consideration of technical and nontechnical issues related to large complex systems; and 7) flexibility - the challenges associated with the ability to add, adjust, or remove both physical components and functions (Jaradat, 2015; Keating, 2008). These challenges, which are commonly found in complex systems, blur the lines between technical, social, organizational, managerial, and policy considerations (Boardman \& Sauser, 2006; DeLaurentis, 2005; Gorod, Sauser, \& Boardman, 2008; Jaradat, Keating, \& Bradley, 2018; Nagahi et al., 2020a). To address these challenges, it is necessary to build a cadre of qualified employees who can take a more holistic approach to effectively engage in complex systems. With the approach proposed in this study, organizations can select and hire candidates based on their systems thinking skills, including Complexity, Autonomy, Interaction, Change, Uncertainty, Hierarchical View, and Flexibility (Jaradat, 2015; Jaradat et al., 2018; Jaradat et al. 2019; Nagahi et al., 2020b). This new approach can supplement the current methods 
used to hire candidates and can be useful to identify candidates for positions. For example, if a specific job position requires an individual with high-level systemic thinking skills, then it is appropriate to hire a more "holistic" systems thinker. On the other hand, if the position requires individuals with a focus on a reductionism-based approach, then it is appropriate to select a reductionist-oriented thinker.

There is a literary gap regarding the utilization of systems thinking when making hiring decisions in order to increase an organization's ability to respond effectively to organizational complex systems problems. The primary goal of this research is to use systems thinking skills as a supplemental selection tool for hiring prospective employees. The aim is to rank all applicants based on their systems thinking skills and then to hire the candidates most in line with the organization's strategy. The intent is not to criticize the current hiring methods but to provide a method to supplement the current screening and selection process. According to personnel selection literature, we have identified two important strategies for ranking new applicants. One is to find applicants who are most aligned with the level of systems thinking skills needed for a specific position requirement, and the second is to find applicants who possess the highest systems thinking skills among a pool of candidates. An established optimization tool will be applied to locate prospective employees. The $L_{p}$ metric will be implemented to deal with Job Fit Recruiting strategy, whereas ELECTRE III will be used as a Flexible Recruiting strategy. Fuzzy logic will be applied to derive the necessary weights implemented in the selected Multi-Criteria Decision-Making (MCDM) tools with the consideration of a vague preference of managers under the uncertain decision-making environment.

The goal behind the proposed recruiting framework can be classified as two folds. First, to develop a comprehensive employee selection criterion by utilizing seven dimensions of systems thinking. The proposed recruiting framework will serve as a supporting tool for the top management to make appropriate hiring decisions, along with other traditional recruiting procedures. Second, to develop a new recruitment framework that will assist the recruiters in finding the right candidate to fit the posted job position based on the candidate's skillset.

The existing recruiting tools and methods are incomplete in the sense that they do not consider individuals' systems thinking skills in identifying the most suitable employee for a specific position depending on the skills requirements of that position. These skills are important to identify, especially with the increasing complexity and uncertainty surrounding work environments. The identifications of these skills will allow the right positioning and recruitment of individuals that will fit the skills levels requirements of the job. Thus, enhance work performance. In an attempt to close this gap, this research introduces a new expert system tool to expert HRM professionals to help recruiters classify employees based on their systems thinking skills. Since recruitment is a decision-making process, this tool implements MDCM methods to 
help classify employees based on their systems thinking skills. The contributions of the study with respect to theoretical, practical and methodological dimensions of the proposed framework are discussed below.

\subsection{Contribution of the Study}

\subsubsection{Theoretical Dimension}

Although systems thinking has been around for decades, there are insufficient tools and techniques purposefully designed to deal with complex socio-technical problems. At best, some tools measure only one or two systems thinking skills (Plate, 2008; Hopper \& Stave, 2008; Dolansky \& Moore, 2013). Many of the current tools are designed for specific domains such as education to test student systems thinking skills (Frank, 2002; 2010; Camelia \& Ferris, 2016). These techniques, while they might satisfy a specific need, have not been designed or specifically structured to facilitate solutions to socio-technical problems. The review of relevant literature also shows that there are few systems thinking tools and techniques specifically designed to deal with complex system problem domains. Because current complex systems challenges can limit an organization's ability to engineer and manage socio-technical systems, it is essential to have a cadre of qualified individuals who can take a more holistic 'systemic' approach to deal with complex system problems.

The proposed framework offers an established instrument to expert HRM professionals for assessing and screening of prospective employees based on their systems thinking skills level with the consideration of uncertainties in the complex decision-making environment using the fuzzy linguistic approach. This framework works as an expert system to identify the most appropriate candidates for an organization to enhance the organization's human capital by matching individuals' skills with job requirements. The proposed framework is implemented in a real case study of a large organization in the US. The novelty of the work is that it provides the first framework in the literature that evaluate a pool of applicants according to their level of systems thinking skills, and then sort them consistent with the recruitment strategy and workforce needs of the organization through Job Fit Recruiting and Flexible Recruiting strategies.

- Job Fit Recruiting: The novelty of the proposed expert framework is to evaluate and rank the systems thinking capability of prospective employees based on the degree of the work complexity in the organization (based on HRM professional feedback) for the specific job.

- Flexible Recruiting: The intent is to screen the pool of prospective employees based on their systems thinking skills scores to find the candidate with the highest level of systems thinking based on seven systemic skills dimensions while controlling vagueness and uncertainties of complex decision making using the fuzzy linguistic approach. 


\subsubsection{Practical Dimension}

Feeling motivated and well-fit for a job enhances employees' levels of comfort and performance, allows them to better serve the entity they work for, and successfully grow within that entity. In addition to the traditional recruiting tools, researchers should invest in looking into employees' mindsets and their impact on companies and industries. There is a lack of research that combines individuals' systems thinking skills with current decision-making tools.

The current study is intended to assess the systems thinking skills of existing employees in order to better fit them in the organization. This research sets the basis for new recruiting tools that can mimic the decisionmaking aptitude of expert recruiters to match employers' needs and thus, reducing turnover and cutting the training cost. Besides individuals' systems skills, the proposed framework can be expanded to include personality traits, level of problem-solving ability, resource management capacity, content, and social skills. The framework can also be enhanced, making use of more advanced, new recruiting methods that work better with these traits.

\subsubsection{Methodological Dimension}

Because of the increasing complexity, decision making is becoming a vital process in organizations. The recruitment process is an important phase where organizations utilize decision making to select the right candidates for the job requirements. When selecting a candidate, an organization must have a precise selection criterion to match them to the job (Gamage, 2014). In the proposed recruiting framework, the researchers used systems thinking skills as a criterion to screen prospective candidates and sort them using fuzzy MCDM methods. Unlike classical MCDM approaches, fuzzy MCDM can obtain more sensitive results in vague decision-making environments. The newly developed recruitment framework can be used to evaluate candidates based on their systems thinking skills and help recruiters to perform Job Fit Recruiting or Flexible Recruiting to find the best candidate.

The following paper is divided into five sections. Section two provides an overview of systems thinking approaches, recruiting strategies, and various MCDM techniques. Section three discusses the integration of systems thinking skills and $L_{p}$ metric/ELECTRE III approaches to satisfy the organization's recruitment strategy. Section four presents a case study to demonstrate the proposed approach. Section five shows the results comparison and sensitivity analysis. The paper ends with concluding thoughts, limitations, and future research in section six. 


\section{Prior Studies}

This literature review provides an overview of systems thinking along with the corresponding instruments. An overview of recruitment and selection strategies are discussed next. The last part of the literature section discusses several classic MCDM approaches.

\subsection{Overview of Systems Thinking Approaches}

Systems thinking enables individuals to address complex system problem domains using a new level of thinking (Richmond, 2000). Merino and Farr (2010) stated that "systems thinking can provide a valuable capability for engineering managers to more effectively deal with complex problems" (p. 265). Olszewski (2014) demonstrated that systems thinking methods can help industrial engineers to better understand their job duties in different domains of industrial engineering, including project management, process improvement, engineering economics, production planning and control, performance metrics, logistics, and other areas. Atwater, Kannan, and Stephens (2008) emphasized the cultivation of systems thinking in graduate management programs and stressed that systems thinking would benefit business curriculum in different areas such as strategy, operations management, operations research, just-in-time production, and supply chain management.

Some approaches were investigated to evaluate the capability of systems thinking. Jaradat (2015) developed an instrument to determine individuals' level of systems thinking skills to deal with complex organizational problems. The instrument was developed based on complex system attributes extracted by grounded theory coding. The instrument measures an employee's predisposition for systems thinking skills in seven dimensions (shown in Table 1); these skills determine an individual's inclination to work with the complex systems problem domain.

Table 1. Seven Dimensions of Systems Thinking Skills Instrument (Adopted from Jaradat \& Keating, 2016).

\begin{tabular}{lll}
\hline \hline Less Systemic (Reductionist) & Dimension & More Systemic (Holistic) \\
\hline $\begin{array}{l}\text { Simplicity (S): Avoid uncertainty, work on linear } \\
\text { problems, prefer the best solution, and prefer } \\
\text { small-scale problems. }\end{array}$ & $\begin{array}{l}\text { Level of Complexity: Comfort with } \\
\text { multidimensional problems and limited } \\
\text { system understanding. }\end{array}$ & $\begin{array}{l}\text { Complexity (C): Expect uncertainty, work } \\
\text { on multidimensional problems, prefer a } \\
\text { working solution, and explore the } \\
\text { surrounding environment. }\end{array}$ \\
\hline $\begin{array}{l}\text { Autonomy (A): Preserve local autonomy, a trend } \\
\text { more toward an independent decision and local } \\
\text { performance level. }\end{array}$ & $\begin{array}{l}\text { Level of Autonomy: Balance between } \\
\text { local-level autonomy versus system } \\
\text { integration. }\end{array}$ & $\begin{array}{l}\text { Integration (G): Preserve global integration, } \\
\text { a trend more toward dependent decisions and } \\
\text { global performance. }\end{array}$ \\
\hline $\begin{array}{l}\text { Isolation (N): Inclined to local interaction, follow } \\
\text { a detailed plan, prefer to work individually, enjoy } \\
\text { working in small systems, and interested more in } \\
\text { cause-effect solution. }\end{array}$ & $\begin{array}{l}\text { Level of Interaction: } \\
\text { Interconnectedness in coordination and } \\
\text { communication among multiple } \\
\text { systems. }\end{array}$ & $\begin{array}{l}\text { Inclined to global interactions, follow the } \\
\text { general plan, work within a team, and } \\
\text { interested less in identifiable cause-effect } \\
\text { relationships }\end{array}$ \\
\hline $\begin{array}{l}\text { Resistance to Change (V): Prefer considering few } \\
\text { perspectives, over-specify requirements, focus } \\
\text { more on internal forces, like short-range plans, } \\
\begin{array}{l}\text { tend to settle things, and work best in a stable } \\
\text { environment. }\end{array}\end{array}$ & $\begin{array}{l}\text { Level of Change: Comfort with rapidly } \\
\text { shifting systems and situations. }\end{array}$ & $\begin{array}{l}\text { Tolerant of Change (Y): Prefer considering } \\
\text { multiple perspectives, underspecify } \\
\text { requirements, focus more on external forces, } \\
\text { like long-range plans, keep options open, } \\
\text { and work best in a changing environment. }\end{array}$ \\
\hline
\end{tabular}




\begin{tabular}{lll}
\hline \hline $\begin{array}{l}\text { Stability (T): Prepare detailed plans beforehand, } \\
\text { focus on the details, uncomfortable with } \\
\text { uncertainty, believe the work environment is under } \\
\text { control, and enjoy objectivity and technical } \\
\text { problems. }\end{array}$ & $\begin{array}{l}\text { Level of Uncertainty: Acceptance of } \\
\text { unpredictable situations with limited } \\
\text { control. }\end{array}$ & $\begin{array}{l}\text { Emergence (E): React to situations as they } \\
\text { occur, focus on the whole, comfortable with } \\
\text { uncertainty, believe the work environment is } \\
\text { difficult to control and enjoy subjectivity and } \\
\text { non-technical problems. }\end{array}$ \\
\hline $\begin{array}{l}\text { Reductionism (R): Focus on particulars and } \\
\text { prefer analyzing the parts for better performance. }\end{array}$ & $\begin{array}{l}\text { Hierarchical View: Understanding } \\
\text { system behavior at the whole versus } \\
\text { part level. }\end{array}$ & $\begin{array}{l}\text { Holism (H): Focus on the whole, interested } \\
\text { more in the big picture, and interested in } \\
\text { concepts and abstract meaning of ideas. }\end{array}$ \\
\hline $\begin{array}{l}\text { Rigidity (D): Prefer not to change, like determined } \\
\text { plans, not open to new ideas, and motivated by } \\
\text { routine. }\end{array}$ & $\begin{array}{l}\text { Level of Flexibility: Accommodation of } \\
\text { change or modifications in systems or } \\
\text { approaches. }\end{array}$ & $\begin{array}{l}\text { Flexibility (F): Accommodating to change, } \\
\text { like a flexible plan, open to new ideas, and } \\
\text { unmotivated by routine. }\end{array}$ \\
\hline
\end{tabular}

\subsection{Recruiting Strategies}

The purpose of recruiting is to find the best-qualified candidates for an organization's workforce because "people make the place" (Schneider, 1987). Selecting the right people for the job constitutes a source of competitive advantage for an organization (Hunter, Schmidt \& Judiesch, 1990). A recruitment and selection system should concentrate on selecting the most appropriate individuals for the organization's jobs based on sufficient qualified applicants (Beardwell \& Wright, 2002; Rynes \& Barber, 1990). Salgado, Viswesvaran, and Ones (2001) summarized several methods to assess potential candidates' suitability for a position, including (1) cognitive ability, (2) physical and perceptual ability, (3) personality, (4) job knowledge, (5) work sample and simulations, (6) interviews, (7) biodata, and (8) assessment center. In this study, we focus on recruiting prospective employees by considering their cognitive abilities related to systems thinking skills.

Wright and Snell (1998) identified two major recruiting strategies in strategic Human Resource Management (HRM) literature: 1) Job Fit strategy and 2) Flexible strategy. Job Fit strategy aims at hiring the most appropriate candidate for a specific position while Flexible strategy is used for general recruiting without a specific position in mind. Extensive prior work that studied HRM practices concluded that the Job Fit strategy should focus on the fit between an organization's strategy and a potential candidate's skills and capabilities; consequently, the candidates that match the organization's strategy most will be selected to fill the job vacancies (e.g., Gerstein \& Reisman, 1983; Gupta, 1984; Hambrick \& Mason, 1984; Kerr, 1982; Olian \& Rynes, 1984). The Flexible strategy, on the other hand, concentrates on building a selection system that is more compatible with the emergent and rapidly changing requirements found in complex and dynamic environments (e.g., Kerr \& Jackofsky, 1989; Lengnick-Hall \& Lengnick-Hall, 1988; Milliman, Glinow, \& Nathan, 1991; Snow \& Snell, 1993). This strategy identifies qualified candidates who can improve the general ability of the organization to compete in emergent and turbulent environments (Snell, Youndt \& Wright, 1996). Research shows that most organizations adopt both recruiting strategies to select the right candidates (Wright \& Snell, 1998). 


\subsection{Classic MCDM Approaches}

MCDM dates back to the 1960s and is considered one of the fastest-growing branches of operations research, producing around seventy MCDM approaches during the last decades (Alias, Hashim, \& Samsudin, 2008). These approaches are developed to 1) assist decision-makers in the selection of alternatives under several conflicting criteria, and 2) establish more advanced methods for practitioners to achieve optimal solutions under conflicting objectives (Wiecek, Ehrgott, Fadel, \& Figueira, 2008).

The weighted sum model (WSM) and the weighted product model (WPM) are the two most commonly used MCDM methods (Triantaphyllou, 2000). The two models are similar except for the difference in the calculation of alternatives' scores. While the WPM method raises the performances' scores to the power of the weights, the WSM method multiplies them. The Analytic Hierarchy Process (AHP), introduced by Saaty in 1977, is another widely used approach. The AHP is a useful approach that can be used to reduce complexity and help the decision-maker arrive at the best decisions. This method uses a series of pairwise comparisons to support the decision-making process and ensure the consistency of the decision maker's evaluations. Following Saaty's (1977) AHP process, several adjusted approaches were developed to rectify AHP drawbacks (Saaty, 1990, 2008, 2013). Beyond WSM, WPM, and AHP, some other proposed methods like the Technique for Order of Preference by Similarity to Ideal Solution (TOPSIS), Elimination and Choice Expressing Reality III (ELECTRE III), and the Preference Ranking Organization METHod for Enrichment of Evaluations (PROMETHEE) are also used and attract consistent attention from both academia and industry (Aruldoss, Laxmi, \& Venkatesan, 2013). The TOPSIS method measures the geometric distance between the ideal solution and each alternative's performance with the best alternative being the one with the closest distance to the ideal solution (Assari \& Assari, 2012). The ELECTRE is a powerful MCDM technique proposed by Bernard Roy (1968). The ELECTRE methods were developed as a series of evolutions such as ELECTRE I, ELECTRE II, ELECTRE III, ELECTRE IV, ELECTRE IS, and ELECTRE TRI (Figueira, Salvatore, \& Matthias, 2005). The models were built with the focal concepts of concordance, discordance, and outranking (Hashemi, Hajiagha, Zavadskas, \& Mahdiraji 2016). The ELECTRE III is an advanced version of the ELECTRE methods and is considered one of the most important methods in MCDM. It outperforms the other approaches in its ability to handle the uncertainties and inaccuracies that come with the data (Marzouk, 2011). The PROMETHEE method represents another class of decision-making approaches for outranking developed in the 1980s by Brans and Vincke (Athawale \& Chakrabort, 2010). These methods are characterized by their simplicity and stability (Brans, Vincke, \& Mareschal, 1986). The PROMETHEE allows the decision-makers to use PROMETHEE I to get a partial preorder or PROMETHEE II to get the complete ranking. 
One of the most significant challenges in implementing MCDM is selecting a suitable method for the problem at hand. Using the wrong approach often results in incorrect decisions, wastes manpower, and increases the cost. Hence, selecting a fitting MCDM method is an essential step in the decision process (Singh \& Malik, 2014). Although there is a vast body of literature discussing the importance of systems thinking and the necessity of organizations to recruit candidates with systems thinking skills, to the best of our knowledge, no study has utilized systems thinking with the 7-dimensions as selection criteria for hiring new employees. To fill this gap, the focus of this study is to include systems thinking skills as a criterion in the selection process using the two major HRM strategies and then integrating MCDM approaches to identify the most appropriate candidates. Below is a summary of the research gaps that will be addressed in this paper.

- Utilizing the 7-dimensions of systems thinking (as introduced in Table 1) as the selection criteria to hire new employees.

- Connecting systems thinking and MCDM to develop a new selection approach that can be used as a supplemental recruiting method for organizations.

\section{Proposed Recruiting Approach}

The study aims to assess candidates' systems thinking skills and rank them based on two recruiting strategies: Job Fit and Flexible. In some cases, an organization needs to fill a specific position that does not necessarily require candidates with a high systems thinking skillset in all the seven dimensions. In this case, human resource managers will use the Job Fit Recruiting strategy and look for potential candidates with the systems thinking skills that best match the position requirement (Scenario I). In some other cases, an organization might look for candidates with the highest systems thinking skills among a pool of prospective employees (Scenario II). The second scenario is categorized as the Flexible Recruiting strategy. Based on the organization's selection criteria, one of these two strategies will be chosen as a recruitment strategy. To implement these two strategies within an organization's recruitment system, we chose two mathematical methods to rank and classify the candidates, the $L_{p}$ metric and the ELECTRE III.

Job Fit Recruiting is concerned with identifying candidates with systems thinking capabilities closest to the organization's requirements. Since the $L_{p}$ metric method measures this closeness by calculating the difference between the organization's requirements and the candidate's systems thinking skill; it can be implemented to rank the potential candidates.

For organizations facing increased levels of complexity and requiring staff with a profound understanding of complex systems management, the Flexible Recruiting strategy is useful because it aims to identify and rank candidates from highest to lowest based on their systems thinking levels. The ELECTRE 
III method is adopted for use with Flexible Recruiting. Figure 1 summarizes the two methods and the corresponding recruiting strategies.

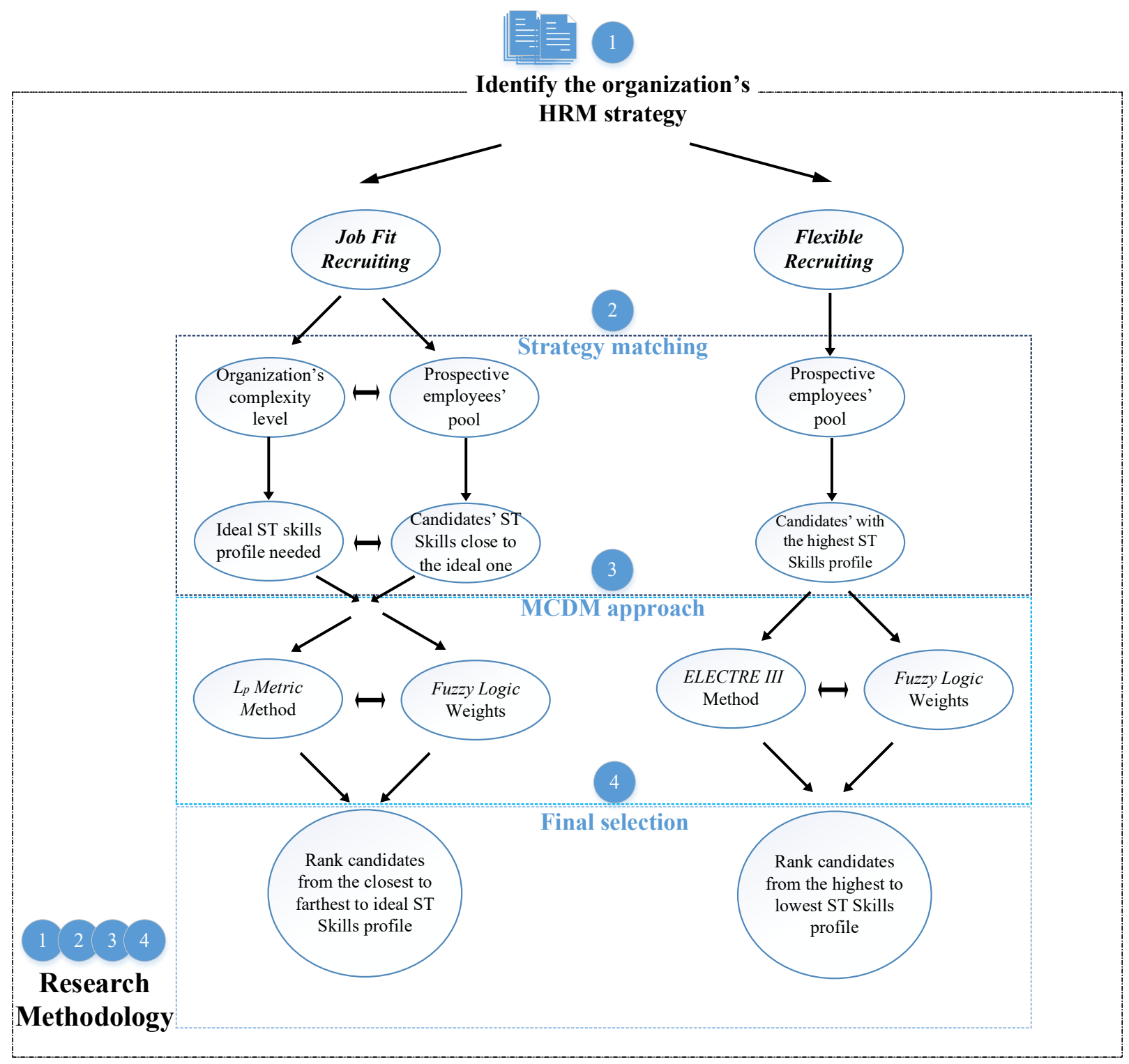

Figure1. The Research Methodology

\subsection{Job Fit Recruiting Strategy}

When being recruited for one open position, candidates have to undergo a comprehensive review consisting of specific recruitment stages. These stages depend on the organization's strategies for employee selection and work as a guide to support the recruiter's decision-making in the targeted position. Within different organizations and environments, employees will be required to have specific systems thinking 
skills, so it is a better practice to search for prospective employees who most fit the organization's level of complexity.

The systems thinking (ST) skills instrument developed by Jaradat (2015) is used to measure the potential candidates' systems thinking skills. The instrument consists of seven dimensions, Complexity, Autonomy, Change, Interaction, Uncertainty, Hierarchical View, and Flexibility, as introduced in Table 1, and each defines a way of thinking and an individual score. Although these seven dimensions are used as criteria for employee selection, it is difficult to weigh them because candidates differ from each other and maybe better in some criteria and worse in others. No single criterion can adequately demonstrate the value of each candidate. For this reason, the MCDM approaches are necessary to incorporate the seven dimensions in the candidate's selection process. Although a tremendous number of MCDM tools are presented in the literature, the $L p$ metric was chosen and applied to the systems thinking dimensions in the proposed approach.

\subsubsection{Lp Metric}

Mathematically, the $L_{p}$ metric measures the distance between a vector $x$ containing $k$ criteria evaluations and a vector $y$ containing the ideal values. In this study, the ideal values represent the required performance of each systems thinking skills dimension for the potential open position. The $w_{j}$ denotes the weight for each dimension. The dimensional weights are usually difficult to obtain in a complex decision-making environment, and therefore, we use fuzzy logic to capture these uncertainties. The distance between the two vectors is calculated as follows (Deza \& Deza, 2009, p.102),

$$
\|x-y\|_{p}=\left[\sum_{j=1}^{k} w_{j}\left|x_{j}-y_{j}\right|^{p}\right]^{1 / p} \text { With } \mathrm{p}=1,2, \ldots, \infty
$$

Since the ideal solution is difficult to achieve, the $L_{p}$ metric is used to calculate the closeness of each solution to the ideal solution. The alternative with the closest distance is the identified target. The commonly used values of ' $p$ ' are 1,2, and $\infty$. In this study, we use the $L_{1}$ metric. Below are the general steps used to determine the rankings of the $L_{1}$ metric (Ravindran, 2016).

Step 1: Determine the ideal solution for each criterion.

Step 2: Implement the $L_{1}$ metric to measure the distance between each candidate's scores for each criterion and the ideal solution. The $L_{1}$ metric for each employee is calculated as follows (Eq. 1, $p=1)$

Step 3: Rank the candidates based on the $L_{1}$ metric results. The candidate with the lowest $L_{1}$ is ranked first. 


\subsubsection{Fuzzy Logic for Weight Determination}

Although Zadeh introduced the term "fuzzy logic" in 1965, the idea of fuzzy logic actually began in the 1920s. The significant difference between classical logic and fuzzy logic is the way true and false for the conclusions are interpreted. Classical logic uses conclusions of true and false, while fuzzy logic uses true and false conclusions as a mathematical model of vagueness, meaning there is a "grey" field between "true" and "false." Fuzzy logic has many advantages in real-world applications as it can evaluate and derive approximate conclusions when dealing with vague and uncertain values (Yang \& Li, 2002; Ma, Kremer, \& Ray, 2018), and it outperforms other techniques of uncertainty representations like probability theory, imprecise probability theory, and subjective probability theory (Ye et al., 2015).

Among the extensive implementations of fuzzy logic, the fuzzy linguistic application is the most widely used (e.g., Liu, Ren, Wu, \& Lin, 2013; Ma \& Kremer, 2015). By replacing the typical cardinal scale, the fuzzy linguistic approach (Zadeh, 1975a, 1975b, 1975c) provides a basis for dealing with the subjective nature of human decisions (Celotto, Loia, \& Senatore, 2015). In a complex decision-making environment, it is difficult to capture the real preference of decision-makers because of the existing vagueness and uncertainties. The fuzzy linguistic approach is one of the best approaches to handle these uncertainties (Ma \& Kremer, 2016). In this study, the uncertainty of preference will be captured through the weighting of each of the systems thinking skills dimension. The weights are evaluated using a rating scale of five levels: least important, less important, moderately important, more important, and most important. The triangular membership function is then applied to represent and convert the fuzzy numbers. Triangular membership functions can be found in many applications such as product development analysis because of its simplicity in calculation and interpretation (Delgado 1993; Bufardi et al. 2004). Table 2 presents the linguistic variable levels along with corresponding fuzzy sets.

Table 2. Linguistic Variable Level and Corresponding Fuzzy Set.

\begin{tabular}{ll}
\hline \hline Weight Linguistic Variable Level & Fuzzy Set \\
\hline Least Important & $(0.0,0.15,0.3)$ \\
Less Important & $(0.2,0.40,0.6)$ \\
Moderately Important & $(0.4,0.55,0.7)$ \\
More Important & $(0.6,0.75,0.9)$ \\
Most Important & $(0.8,0.90,1.0)$ \\
\hline
\end{tabular}

Fuzzy evaluation generates several fuzzy sets, and an integrative method is needed to combine and simplify the sets. Here, we adopt fuzzy arithmetic methods and provide the $\alpha$-cut method as described by Dutta et al. (2011) as follows:

$a=\left(a_{1}, a_{2}, a_{3}\right)$, and $b=\left(b_{1}, b_{2}, b_{3}\right)$ are two fuzzy sets with the following triangular membership functions: 


$$
\begin{aligned}
& \mu_{a}(x)= \begin{cases}\frac{x-a_{1}}{a_{2}-a_{1}}, & a_{1} \leq x \leq a_{2} \\
\frac{a_{3}-x}{a_{3}-a_{2}}, & a_{2} \leq x \leq a_{3}\end{cases} \\
& \mu_{b}(x)= \begin{cases}\frac{x-b_{1}}{b_{2}-b_{1}}, & b_{1} \leq x \leq b_{2} \\
\frac{b_{3}-x}{b_{3}-b_{2}}, & b_{2} \leq x \leq b_{3}\end{cases}
\end{aligned}
$$

Then $\alpha$-cut of fuzzy numbers $a$ and $b$ will be presented as in the following:

$$
\begin{aligned}
& a^{\alpha}=\left[\left(a_{2}-a_{1}\right) \alpha+a_{1}, a_{3}-\left(a_{3}-a_{2}\right) \alpha\right] \\
& b^{\alpha}=\left[\left(b_{2}-b_{1}\right) \alpha+b_{1}, b_{3}-\left(b_{3}-b_{2}\right) \alpha\right]
\end{aligned}
$$

The fuzzy number operations will be derived as:

$$
\begin{aligned}
& a^{\alpha}+b^{\alpha}=\left[a_{1}+b_{1}+\left(a_{2}-a_{1}+b_{2}-b_{1}\right) \alpha, a_{3}+b_{3}-\left(a_{3}-a_{2}+b_{3}-b_{2}\right) \alpha\right] \\
& a^{\alpha}-b^{\alpha}=\left[a_{1}-b_{3}+\left(a_{2}-a_{1}+b_{3}-b_{2}\right) \alpha, a_{3}-b_{1}-\left(a_{3}-a_{2}+b_{2}-b_{1}\right) \alpha\right] \\
& a^{\alpha} \times b^{\alpha}=\left[\left(\left(a_{2}-a_{1}\right) \alpha+a_{1}\right) \times\left(\left(b_{2}-b_{1}\right) \alpha+b_{1}\right),\left(a_{3}-\left(a_{3}-a_{2}\right) \alpha\right) \times\left(b_{3}-\left(b_{3}-b_{2}\right) \alpha\right)\right] \\
& \frac{a^{\alpha}}{b^{\alpha}}=\left[\frac{\left(a_{2}-a_{1}\right) \alpha+a_{1}}{b_{3}-\left(b_{3}-b_{2}\right) \alpha}, \frac{a_{3}-\left(a_{3}-a_{2}\right) \alpha}{\left(b_{2}-b_{1}\right) \alpha+b_{1}}\right]
\end{aligned}
$$

Fuzzy operations facilitate the combination of many fuzzy sets into a single fuzzy set. However, it is still difficult to make relevant decisions because the triangular fuzzy set covers three numbers. Chen and Hwang (1992) developed a left and right boundary method to convert a fuzzy set into a crisp number, which makes decision-making more straightforward. In this method, fuzzy maximizing and minimizing sets are used to defuzzify the fuzzy number.

$$
\begin{aligned}
& f_{\text {max }}(x)=\left\{\begin{array}{cc}
x, & 0 \leq x \leq 10, \\
0, & \text { otherwise }
\end{array}\right. \\
& f_{\text {min }}(x)=\left\{\begin{array}{cr}
10-x, & 0 \leq x \leq 10, \\
0, & \text { otherwise }
\end{array}\right.
\end{aligned}
$$

When given a triangular fuzzy number, FPII defined as $f_{F P I I}: R \rightarrow[0,10]$, with a triangular membership function, the right and left scores of FPII can be obtained, respectively, as

$$
\begin{aligned}
& U_{R}(F P I I)=\sup _{x}\left[f_{F P I I}(x) \wedge f_{\text {max }}(x)\right] \\
& U_{L}(F P I I)=\sup _{x}\left[f_{F P I I}(x) \wedge f_{\text {min }}(x)\right]
\end{aligned}
$$

The total score of FPII can be obtained by combining the left and right scores. The total score of FPII is then used to determine the fuzzy number ranking, which is defined as:

$$
U_{T}(F P I I)=\left[U_{R}(F P I I)+10-U_{L}(F P I I)\right] / 2
$$


For example, a fuzzy set $(0.2,0.23,0.5)$ is converted to a single number of 0.35 by using the left-right method. The single numbers will be normalized to obtain weights.

\subsection{Flexible Recruiting}

Organizations operate in turbulent and rapidly changing environments. Hence, the systems thinking skills corresponding to the current level of complexity might not be stable or fixed. As a result, it is not advisable to seek employees based on the current level of environmental complexity. In these cases, it is better to use the Flexible Recruiting strategy. When the potential candidates are identified, evaluations are undertaken to determine each applicant's level of systems thinking skills. Given the evaluations for the seven dimensions of systems thinking, MCDM will then be used to rank the candidates. ELECTRE III method is one of the well-established MCDM methods and will be chosen to be integrated with fuzzy logic to rank the potential candidates depending on their systems thinking skills.

\subsubsection{ELECTRE III Approach}

Data fed to MCDM problems are based on decision-makers' evaluations. As a result, these data are accompanied by high levels of uncertainty and ambiguity. The ELECTRE III method, first introduced by Roy in 1990, takes into account this uncertainty by introducing three thresholds:

- Preference threshold $p$ : is the disparity that allows a decision-maker to greatly prefer a solution over another for a specific criterion $j$. Solution $b$ is preferred to solution $a$ regarding criterion $j$ if:

$g_{j}(b)>g_{j}(a)+p\left(g_{j}(a)\right)$

where $g_{j}$ being the individual partial preference function.

- Indifference threshold $q$ : is usually a relatively small difference under which the decision-maker prefers one alternative over another for a criterion $j$. Solution $b$ is not preferred to solution $a$ and vice versa if:

$$
g_{j}(b) \geq g_{j}(a)+q_{j}\left(g_{i}(a)\right)
$$

- Veto threshold $v$ : accounts for the size of differences between alternatives with regard to each criterion. Thus, differences with negligible importance are not mistaken for those with significant importance. Solution $b$ cannot dominate solution $a$ if $b$ performs better than $a$ by a difference greater than or equal to the veto threshold, i.e., if:

$$
g_{j}(b) \geq g_{j}(a)+v_{j}\left(g_{i}(a)\right)
$$

These thresholds allow us to express relations correctly by taking into account how big or small the differences are.

In addition to the three thresholds discussed above, ELECTRE III also introduces four binary relations: indifference (I), strong preference (P), light preference (Q), and non-comparability (R). These relations help 
in the generation of preferences according to the axiom of partial comparability on which the ELECTRE III method is based.

ELECTRE III starts with a decision matrix evaluating performances of alternatives with respect to each criterion (refer to Appendix A). Alternative $a$ is considered to outrank alternative $b$ referring to a criterion $j$ when $g_{j}(b)>g_{j}(a)$. The aim of the three thresholds is to define the statement $a S b$ for every two alternatives a and $\mathrm{b}$. The $a S b$ states that alternative $a$ outranks alternative $b$ in terms of a criterion $j$ if there exists a solid argument to support that alternative $a$ is not less than or better than alternative $b$ in the majority of the criteria and not significantly less in the remaining criteria. Consequently, $a S_{j} b$ is determined for each criterion. A criterion $j$ supports the statement $a S b$ only if $a S_{j} b$.

The ELECTRE III method depends on the formation of the concordance and the discordance matrices. The role of these matrices is to determine whether the statement $a S b$ is admissible. For $a S b$ to hold, the concordance matrix requires a large number of the criteria, taking into account their importance, to support the statement $a S b$ while the discordance matrix must show that the rest of the criteria that are against the statement $a S b$ do not strongly reject it. Figure 2 presents the process flow of the ELECTRE III approach (Giannoulis \& Ishizaka, 2010). Basically, the ELECTRE III method can be split into two main parts. The first part is concerned with the construction of the outranking relations where the concordance, discordance, and reliability matrices are created, and the second part is concerned with the exploration of the outranking relations and the construction of the final ranking (refer to the rest of this section for more details). 


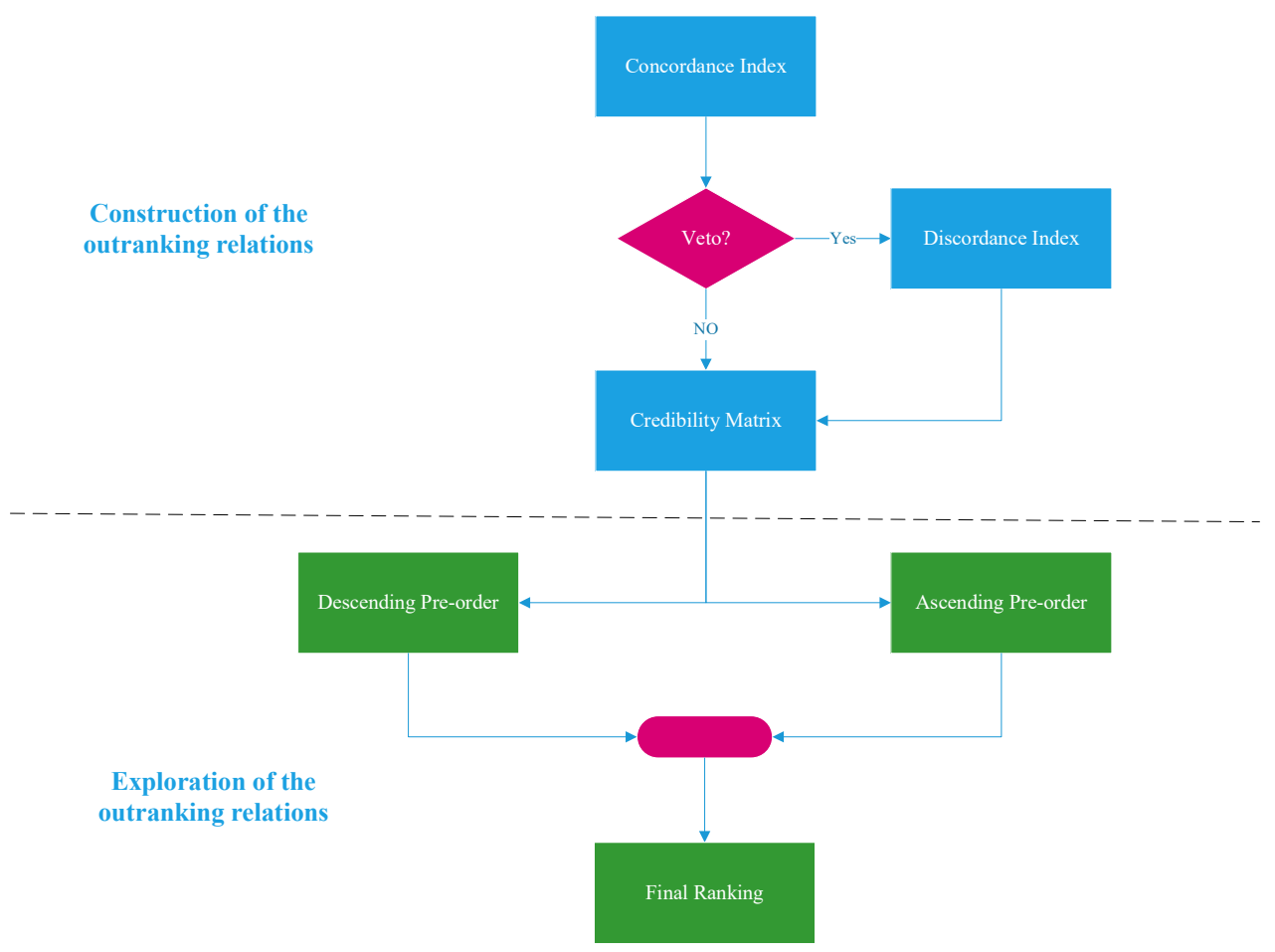

Figure 2. ELECTRE III Process Flow

If the objective functions of all criteria are to be maximized, the concordance matrix elements are obtained using the following relation,

$C(a, b)=\frac{1}{k} \sum_{j=1}^{j} w_{j} c_{j}(a, b)$

Where:

$w_{j}$ : The importance coefficient of criterion $j$ identified by the decision-maker.

$$
\begin{array}{ll}
w=\sum_{j=1}^{m} w_{j} & \\
c_{j}(a, b)=1 & \text { if } g_{j}(a)+q_{j} \geq g_{j}(b), \\
c_{j}(a, b)=0 & \text { if } g_{j}(a)+p_{j} \leq g_{j}(b), \\
c_{j}(a, b)=\frac{q_{j}+g_{j}(a)-g_{j}(b)}{p_{j}-q_{j}}
\end{array}
$$

The thresholds $p_{j}, q_{j}$ and $v_{j}$ should also be identified by the decision-maker and can be set either as constants or as a function of criteria preferences.

The discordance matrix can be calculated once the veto threshold is determined. The statement $a P b$ can be rejected entirely if the inequality $g_{j}(b)>g_{j}(a)+v_{j}$ is conclusive for all criteria. The discordance matrix elements can be obtained using the following equations,

$d_{j}(a, b)=0 \quad$ if $g_{j}(a)+p_{j}>g_{j}(b)$ 
$d_{j}(a, b)=1 \quad$ if $g_{j}(a)+v_{j} \leq g_{j}(b)$

$d_{j}(a, b)=\frac{g_{j}(b)-g_{j}(a)-p_{j}}{v_{j}-p_{j}}$

The most crucial step in the ELECTRE III method is the determination of the reliability matrix, which can be calculated by combining elements of the two previous matrices with the elements $S(a, b)$. The elements of the reliability matrix can be defined using the equations below,

$$
S(a, b)=C(a, b) \quad \text { if } d_{j}(a, b) \leq C(a, b) \text { for every } j
$$

Otherwise

$$
S(a, b)=C(a, b) \prod_{j \in j(a, b)} \frac{1-d_{j}(a, b)}{1-C(a, b)}
$$

Where $j(a, b)$ represents the criteria that have the valid statement $d_{j}(a, b) \leq C(a, b)$.

After the identification of the reliability matrix, the ranking is completed through a structured algorithm that uses two intermediate strategies for ranking, the ascending distillation where solutions are arranged from worst to best and the ascending distillation where alternatives are arranged from worst to best. Building these two pre-rankings is achieved as follows: we first define the maximum values $\lambda_{0}$ of $S(a, b)$ for all pairs of solutions:

$$
\lambda_{0}=\max _{a, b \in A}\{S(a, b)\}
$$

Hence, the parameter $\lambda_{0}$ is considered the cut-off point of outranking $\lambda_{1}$ with $\lambda_{1}=\lambda_{0}-\mathrm{s}\left(\lambda_{0}\right)$. The s $\left(\lambda_{0}\right)$ is called the discrimination threshold and is based on which of the two solutions is chosen. Considering two solutions ( $\mathrm{a}, \mathrm{b})$, we can say that $a$ outranks $b$ if the two following conditions are met:

$$
\mathrm{a} S^{\lambda_{1}} b=\left\{\begin{array}{c}
S(a, b)>\lambda_{1} \\
S(a, b)-S(b, a)>\mathrm{s}(S(a, b))
\end{array}\right\}
$$

\section{Case Study}

This section provides a case study to demonstrate how to use the proposed approach to recruit prospective employees. The case study is developed based on a real recruiting case from a large scale organization located in the United States. To respect confidentiality, the name and type of organization are not disclosed. Two survey instruments developed by Jaradat (2015) and Jaradat and Keating (2016), called "Individual Systems-Thinking Skills" and "Environmental Complexity Demand," are used to collect data for the study. The "Individual Systems-Thinking Skills" instrument collects data from prospective employees of the anonymous organization. The "Individual Systems-Thinking Skills" instrument examines seven 
dimensions of systemic skills (as shown in Table 1) through a 39-question web survey and determines the relative preference for system thinking skills for the prospective employees.

Using data gathered from HRM professionals at the anonymous organization, the "Environmental Complexity Demand" instrument determines the systems thinking skills requirement for the organization by examining the degree of perceived complexity that exists in the organization's environment. The "Environmental Complexity Demand" instrument measures the seven dimensions of systems thinking skills pertaining to the environmental complexity level through a 50-question web-survey (as shown in Table 1). This web-survey is a supervisor-rated survey that gathers HRM professionals' responses regarding the complexity demand of the organization. The combination of candidates' systems thinking skills and HRM professionals' opinions about the systems thinking skills needed within the organization are instructive in understanding the degree to which the organization should fill any existing systems thinking gap associated with the complexity demands of the environment.

In this study, the Job Fit Recruiting strategy used integrated information from the "Environmental Complexity Demand" and "Individual Systems-Thinking Skills" instruments to rank the applicants. The results from the "Environmental Complexity Demand" instrument served as the company's standard requirement for a specific position; then, the results from the "Individual Systems-Thinking Skills" instrument were used to find a more suitable candidate to meet the organization's standard criteria. For the Flexible Recruiting strategy, only results from the "Individual Systems-Thinking Skills" instrument were used to select the candidates with greater systems thinking skills profile among the applicant pool.

\subsection{Job Fit Recruiting}

In the Job Fit Recruiting strategy, the seven dimensions from the systems thinking instrument are used as criteria for alternatives comparison and ranking. Referring to the table in Appendix A, it can be observed that no candidate dominates the others in all seven dimensions; consequently, MCDM methods are required to rank these candidates.

The Job Fit Recruiting strategy looks for the candidate who most closely matches the organization's requirements. To identify these requirements, each HRM professional was asked to complete the “Environmental Complexity Demand" instrument. Scores provided by the HRM professionals are averaged out to get the desired skill level, also referred to as the ideal values for each dimension. In other words, the prospective employees should possess the ideal values for each dimension to engage effectively in complex systems problems in the organization. As shown in Figure 3, the desired skill levels for prospective employees are $20 \%$ for Change, Uncertainty, and Flexibility, around 60\% for Complexity, Interaction, and Hierarchical View, and around $20 \%$ for Integration/Autonmy. The $L_{p}$ metric multi-criteria model was then 
implemented to locate the most suitable candidate. As mentioned in section 2.2, the $L_{p}$ metric measures the distance between a vector $y$ containing evaluations of each dimension for a specific candidate and a vector $x$ containing the ideal values (the requirements). The goal is to identify the candidate with values closest to the ideal values, and the $L_{p}$ metric is one of the simplest, yet the best, methods to achieve that goal.

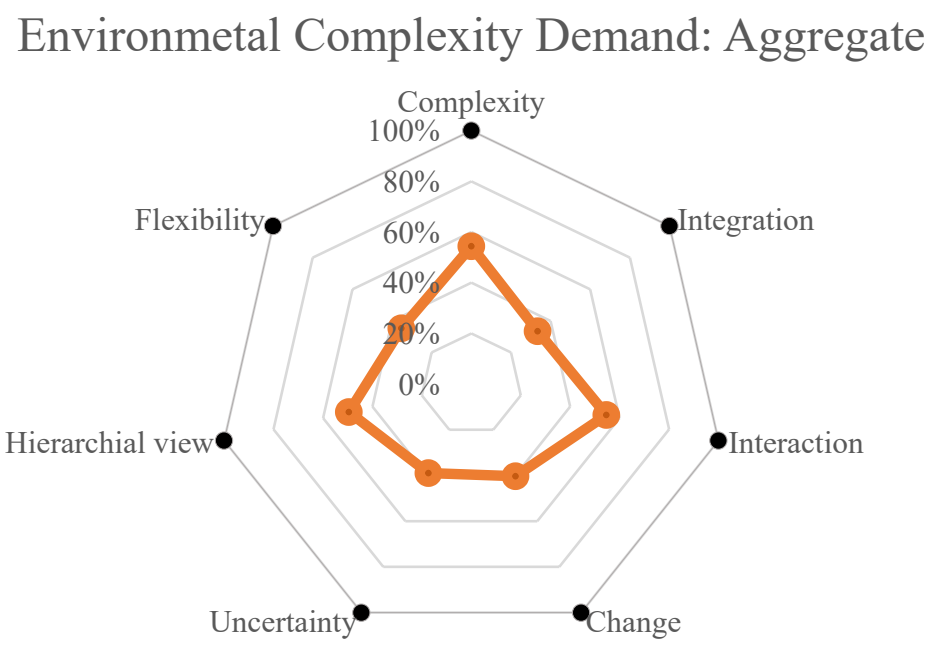

Max 100\%, more systemic

Figure 3. Graphic Depiction of Environment Complexity Demand Dimensions Rated by HRM Professionals Used as the Ideal Values.

The weights for each dimension are obtained using the integration of group decision making and fuzzy logic, and the results are shown in Table 3. Using Eq.1, we calculated the distance between candidates' scores for each dimension and the requirement for that specific dimension. First, we select the highest distance calculated for each alternative. Among the selected distances, we again select the smallest distance. The candidate that holds the smallest distance value is the candidate that best fits the job description with regard to his/her systems skills thinking.

Table 3. Fuzzy Raw Data and Weights

\begin{tabular}{|c|c|c|c|c|c|c|}
\hline Dimension & DM1 & DM2 & DM3 & Fuzzy Average & $\begin{array}{c}\text { Defuzzification } \\
\text { Result }\end{array}$ & $\begin{array}{c}\text { Normalized } \\
\text { Weight }\end{array}$ \\
\hline Level of Complexity & $\begin{array}{c}\text { More } \\
\text { Important }\end{array}$ & $\begin{array}{c}\text { More } \\
\text { Important }\end{array}$ & $\begin{array}{c}\text { Most } \\
\text { Important }\end{array}$ & $(0.67,0.8,0.93)$ & 0.8556 & 0.1498 \\
\hline Level of Autonomy & $\begin{array}{l}\text { Moderately } \\
\text { Important }\end{array}$ & $\begin{array}{l}\text { More } \\
\text { Important }\end{array}$ & $\begin{array}{l}\text { More } \\
\text { Important }\end{array}$ & $(0.53,0.68,0.83)$ & 0.7333 & 0.1284 \\
\hline Level of Interaction & $\begin{array}{c}\text { Most } \\
\text { Important }\end{array}$ & $\begin{array}{l}\text { Moderately } \\
\text { Important }\end{array}$ & $\begin{array}{l}\text { Moderately } \\
\text { Important }\end{array}$ & $(053,0.67,0.8)$ & 0.7222 & 0.1265 \\
\hline Level of Change & $\begin{array}{c}\text { Most } \\
\text { Important }\end{array}$ & $\begin{array}{c}\text { Most } \\
\text { Important }\end{array}$ & $\begin{array}{c}\text { Most } \\
\text { Important }\end{array}$ & $(0.8,0.9,1)$ & 0.9667 & 0.1693 \\
\hline Level of Uncertainty & $\begin{array}{c}\text { More } \\
\text { Important }\end{array}$ & $\begin{array}{c}\text { More } \\
\text { Important }\end{array}$ & $\begin{array}{c}\text { More } \\
\text { Important }\end{array}$ & $(0.6,0.75,0.9)$ & 0.8000 & 0.1401 \\
\hline $\begin{array}{c}\text { Level of Hierarchical } \\
\text { View }\end{array}$ & $\begin{array}{c}\text { Most } \\
\text { Important }\end{array}$ & $\begin{array}{c}\text { Most } \\
\text { Important }\end{array}$ & $\begin{array}{c}\text { Most } \\
\text { Important }\end{array}$ & $(0.8,0.9,1)$ & 0.9667 & 0.1693 \\
\hline Level of Flexibility & $\begin{array}{l}\text { Moderately } \\
\text { Important }\end{array}$ & $\begin{array}{l}\text { Moderately } \\
\text { Important }\end{array}$ & $\begin{array}{c}\text { More } \\
\text { Important }\end{array}$ & $(0.47,0.62,0.77)$ & 0.6667 & 0.1166 \\
\hline
\end{tabular}


Table 4 shows the top 20 candidates selected based on the $L_{1}$ metric method. Employee 97 exhibits the lowest distance deviating from the requirement. Furthermore, ranks number 2-6 display almost the same distance from the ideal values with a difference of three digits compared to the employee ranked first.

Table 4. $L_{p}$ Metric Results

\begin{tabular}{lcccccccccc}
\hline \hline Rank & 1 & 2 & 3 & 4 & 5 & 6 & 7 & 8 & 9 & 10 \\
\hline Employee ID & 97 & 56 & 5 & 93 & 79 & 96 & 52 & 47 & 29 & 44 \\
Distance & 9.93 & 13.15 & 13.19 & 13.30 & 13.38 & 13.39 & 13.98 & 14.23 & 14.16 & 14.65 \\
\hline \hline Rank & 11 & 12 & 13 & 14 & 15 & 16 & 17 & 18 & 19 & 20 \\
\hline Employee ID & 49 & 58 & 2 & 66 & 99 & 87 & 107 & 28 & 11 & 36 \\
Distance & 14.67 & 14.97 & 15.18 & 15.74 & 15.89 & 15.98 & 15.99 & 16.22 & 16.41 & 16.81 \\
\hline
\end{tabular}

\subsection{Flexible Recruiting}

The ELECTRE III method was implemented to conduct a Flexible Recruiting strategy. After identifying alternatives' performances in each criterion and the thresholds (shown in Table 5), the concordance and the discordance matrices are calculated; then, we are able to calculate the reliability matrix. The reliability matrix is considered the most decisive matrix since it provides a favorable outcome on the ranking of the proposed scenarios.

It should be noted that there are no inherently bad or good systems thinking skills profiles. The choice of a systems thinker depends solely on the job description and the level of systems thinking suitable for that specific job. However, with the increased complexity of systems in all fields and domains, high-level systems thinking skills profiles with a holistic view are preferred, especially for managerial positions. In this case, we will identify the candidate with the highest systems thinking skills levels in all dimensions as the best candidate within the application pool. All candidates are ranked from highest to lowest. We use the same weights as in Table 3. Table 5 presents the thresholds necessary to get the ELECTRE III results. These thresholds are determined by the decision-makers of the targeted organization.

Table 5. ELECTRE III Thresholds

\begin{tabular}{|c|c|c|c|c|c|c|c|}
\hline Dimension & $\begin{array}{c}\text { Level of } \\
\text { Complexity }\end{array}$ & $\begin{array}{c}\text { Level of } \\
\text { Autonomy }\end{array}$ & $\begin{array}{l}\text { Level of } \\
\text { interaction }\end{array}$ & $\begin{array}{l}\text { Level of } \\
\text { Change }\end{array}$ & $\begin{array}{l}\text { Level of } \\
\text { Uncertainty }\end{array}$ & $\begin{array}{c}\text { Hierarchical } \\
\text { View }\end{array}$ & $\begin{array}{l}\text { Level of } \\
\text { Flexibility }\end{array}$ \\
\hline Importance threshold (q) & 5 & 5 & 5 & 5 & 5 & 5 & 5 \\
\hline Preference threshold $(p)$ & 40 & 30 & 30 & 25 & 30 & 40 & 20 \\
\hline Veto threshold (v) & 50 & 50 & 50 & 50 & 50 & 50 & 50 \\
\hline
\end{tabular}

In consonance with the criteria and thresholds determined based on the decision maker's choice and with the implementation of fuzzy logic, the most suitable candidates for highly complex systems are employees 21 and 80 who are both ranked first. The top 20 candidates and their corresponding ranks are presented in Table 6. 
Table 6. ELECTRE III Results

\begin{tabular}{llllllllllllllll}
\hline \hline Rank & 1 & 2 & 3 & 4 & 5 & 6 & 7 & 8 & 9 & 10 & 11 & 12 & 13 & 14 & 15 \\
Employee ID & $21^{1}$ & $80^{1}$ & 72 & $27^{2}$ & $6^{2}$ & 46 & $54^{3}$ & $40^{3}$ & $43^{4}$ & $33^{4}$ & 15 & 17 & $3^{5}$ & $105^{5}$ & 85 \\
\hline \hline Rank & 16 & 17 & 18 & 19 & 20 & 21 & 22 & 23 & 24 & 25 & & & & \\
Employee ID & 51 & 8 & 1 & 94 & 45 & 32 & 74 & 4 & 104 & 108 & & & & \\
\hline
\end{tabular}

$1,2,3,4$, and 5 have an identical ranking.

If we refer to the data containing candidates' performances regarding each criterion, we can make sense of the ranking results. All dimensions' levels for employee 21 are above $60 \%$ with $100 \%$ Flexibility and Autonomy. Employee 80 is also 100\% flexible with criteria levels above $80 \%$ except for Change and Uncertainty, which are $33.3 \%$ and $50 \%$, respectively. The rest of the candidates either have low performances in all criteria or the majority of them. For instance, the performances of employee 44 and employee 53 are under $50 \%$ and $60 \%$ respectively for all criteria. All criteria performances for employee 78 are under $40 \%$ except for Flexibility.

\section{Results Discussion and Analysis}

In this section, we will be discussing the ELECTRE III results through a comparison with results obtained from "Technique for Order Preference by Similarity to an Ideal Solution" (TOPSIS). TOPSIS is an MCDM tool first introduced by Hwang and Yoon (1981). The method is based on the concept that the best solution is the one with the smallest generated distance from the ideal best and the highest calculated distance from the ideal worst. The ideal best is the best value attained by alternatives for all criteria, and the ideal worst is the worst value attained by alternatives in all criteria. We implement TOPSIS to choose the best out of all 108 alternatives based on the seven systems skills dimensions treated as decision-making criteria. The weights integrated into the TOPSIS method are the same weights used for the ELECTRE III method generated through fuzzy logic. The TOPSIS ranking is obtained following steps below:

Step 1. Calculate the normalized decision matrix:

The aim of the first step is the normalization of the alternatives' performance matrix to scaled values to allow for criteria comparison. The elements of the matrix are normalized through the following relation:

$$
\overline{r_{l j}}=\frac{r_{i j}}{\sqrt{\sum_{J=1}^{n} r_{i j}^{2}}} \quad i=1,2,3, \ldots, n ; j 1,2,3, \ldots, m .
$$

With $n$ being the number of solutions or alternatives and $m$ the number of criteria (refer to Appendix A). 
Step 2. Calculate the weighted normalized matrix:

Since criteria are often of varying importance, this step allows the integration of weights showing the importance of each criterion. These weights are multiplied by elements of the previous matrix to generate the elements of the weighted normalized matrix.

$v_{i j}=w_{j} \overline{r_{l \jmath}} \quad i=1,2,3, \ldots, n ; j=1,2,3, \ldots, m$

Step 3: Determine the best ideal and worst ideal solutions:

The best and worst values obtained for each criterion are identified.

Best ideal solution: $S^{+}=\left\{v_{1}^{+}, v_{2}^{+}, \ldots, v_{m}^{+}\right\}=\left\{\left(\max _{j} r_{i j} \mid j \in M^{+}\right),\left(\min _{j} r_{i j} \mid j \in M^{-}\right)\right\}$

Worst ideal solution: $S^{-}=\left\{v_{1}^{-}, v_{2}^{-}, \ldots, v_{m}^{-}\right\}=\left\{\left(\max _{j} r_{i j} \mid j \in M^{+}\right),\left(\min _{j} r_{i j} \mid j \in M^{-}\right)\right\}$

$M^{+}$and $M^{-}$represent the sets of criteria with maximum and minimum objectives, respectively.

Step 4: Calculate of the Euclidian distance from the ideal best and ideal worst:

In this step, the difference between each alternative's criteria values, the ideal best $\left(E D_{i}^{+}\right)$, and the ideal worst $\left(E D_{i}^{-}\right)$are calculated. The relationships below are used to generate those differences:

$E D_{i}^{+}=\sqrt{\sum_{j=1}^{m}\left(v_{i j}-v_{j}^{+}\right)^{2}}, \quad i=1,2,3, \ldots, n$.

$E D_{i}^{-}=\sqrt{\sum_{j=1}^{m}\left(v_{i j}-v_{j}^{-}\right)^{2}}, \quad i=1,2,3, \ldots, n$.

Step 5: Calculation of performance score:

$R C_{i}=\frac{E D_{i}^{-}}{E D_{i}^{i}+E D_{i}^{+}}, \quad i=1,2,3, \ldots, n$

Step 6: Ranking alternatives: the alternative with the highest performance score is ranked first, and so on.

Results obtained from TOPSIS (Table 7) showed differences in the ranking compared to the ELECTRE III results. The top three candidates for the ELECTRE III method are employees 21, 80, and 72, while in TOPSIS, the top three are employees 72, 21, and 46. Employee 21 was ranked first by ELECTRE III and second by TOPSIS. Employee 72 got the first rank using TOPSIS but the third rank using ELECTRE III. Employee 80 was ranked second in the ELECTRE III method and ranked sixth using TOPSIS. Employee 46 is ranked fifth by ELCTRE III instead of third in TOPSIS. For both methods, the same 15 employees are among the top 20. Differences among both results are not dispersed but slightly different. Since the same weights were used to generate results for both methods, the difference in ranking is due to the method itself. 
TOPSIS aims at identifying the best ideal and the best worst and comparing alternative performances for each criterion with the ideal best and worst. The closer the solution is to the ideal best and the farther it is from the ideal worst, the better. On the other hand, the ELECTRE III method incorporates additional thresholds and relations to account for the uncertainty inherent in data often estimated by the decision-maker, which the TOPSIS method lacks. ELECTRE III introduces three thresholds of preference, indifference, and veto with four relations of preference, indifference, strong preference, and non-comparability, which makes the ELECTRE III method more reliable than TOPSIS. Overall, results from both methods did not show much difference.

Table 7. TOPSIS Results

\begin{tabular}{lrrrrrrrrrr}
\hline \hline Rank & 1 & 2 & 3 & 4 & 5 & 6 & 7 & 8 & 9 & 10 \\
\hline Employee ID & 72 & 21 & 46 & 74 & 8 & 80 & 51 & 17 & 27 & 105 \\
Performance Score & 0.700 & 0.667 & 0.663 & 0.654 & 0.645 & 0.635 & 0.625 & 0.624 & 0.601 & 0.595 \\
\hline \hline Rank & 11 & 12 & 13 & 14 & 15 & 16 & 17 & 18 & 19 & 20 \\
\hline Employee ID & 6 & 81 & 85 & 23 & 61 & 33 & 40 & 15 & 54 & 38 \\
Performance Score & 0.575 & 0.551 & 0.547 & 0.540 & 0.539 & 0.536 & 0.533 & 0.533 & 0.524 & 0.524 \\
\hline
\end{tabular}

The sensitivity analysis is performed to assess the ranking stability of the solutions with regard to the generated weights by fuzzy logic. Six ranking scenarios result from these combination of weights. Table 8 indicates the combination of different coefficients for different scenarios. Table 9 presents the cases and corresponding ranks.

Table 8. Various Case Scenarios with Different Dimension Weights

\begin{tabular}{cccccccc}
\hline \hline Cases & $\begin{array}{c}\text { Level of } \\
\text { Complexity }\end{array}$ & $\begin{array}{c}\text { Level of } \\
\text { Autonomy }\end{array}$ & $\begin{array}{c}\text { Level of } \\
\text { interaction }\end{array}$ & $\begin{array}{c}\text { Level of } \\
\text { Change }\end{array}$ & $\begin{array}{c}\text { Level of } \\
\text { Uncertainty }\end{array}$ & $\begin{array}{c}\text { Hierarchical } \\
\text { View }\end{array}$ & $\begin{array}{c}\text { Level of } \\
\text { Flexibility }\end{array}$ \\
\hline $\mathbf{1}$ & $1 / 7$ & $1 / 7$ & $1 / 7$ & $1 / 7$ & $1 / 7$ & $1 / 7$ & $1 / 7$ \\
$\mathbf{2}$ & $1 / 12$ & $1 / 12$ & $1 / 12$ & $1 / 12$ & $1 / 12$ & $1 / 12$ & $1 / 2$ \\
$\mathbf{3}$ & $1 / 10$ & $1 / 10$ & $1 / 10$ & $1 / 10$ & $1 / 10$ & $1 / 4$ & $1 / 4$ \\
$\mathbf{4}$ & $1 / 8$ & $1 / 8$ & $1 / 8$ & $1 / 8$ & $1 / 6$ & $1 / 6$ & $1 / 6$ \\
$\mathbf{5}$ & $1 / 8$ & $1 / 8$ & $1 / 8$ & $1 / 8$ & $1 / 12$ & $1 / 12$ & $1 / 3$ \\
$\mathbf{6}$ & $1 / 10$ & $1 / 10$ & $1 / 10$ & $1 / 5$ & $1 / 5$ & $3 / 20$ & $3 / 20$ \\
\hline
\end{tabular}

According to the sensitivity analysis results in Table 9 and the ranking obtained using the fuzzy weights in Table 3, we see that employees $21,80,72,27,6,54,43,33,15,17,3,8,1,94$, and 45 are ranked among the top 20 in all cases and in the original ranking. Employees 46, 105, 85, and 51 are also present among the top 20 but are missing in cases 2 and 5, cases 6 and 2, case 6, and cases 2 and 5, respectively. Employees 32,74 , and 104 are ranked 16,17, and 19 respectively in the original ranking but are missing in all sensitivity analysis cases. Employee 108 is present in cases 2, 4, and 6. Employee 21 is ranked first in all cases, apart from case 3. Employees 21, 72, and 80 are ranked top three in all cases, but the last case where employee 27 is ranked second. In general, we can deduce that the weights do have an effect on the ranking but with a small significance. 
Table 9. Ranking's Result of Different Case Scenarios.

\begin{tabular}{|c|c|c|c|c|c|c|c|c|c|c|c|c|c|c|c|c|c|c|c|c|}
\hline Rank & 1 & 2 & 3 & 4 & 5 & 6 & 7 & 8 & 9 & 10 & 11 & 12 & 13 & 14 & 15 & 16 & 17 & 18 & 19 & 20 \\
\hline $\begin{array}{c}\text { Case 1 } \\
\text { (Employee) }\end{array}$ & 21 & 80 & 72 & 27 & 6 & $54 *$ & $40 *$ & 15 & 46 & 43 & 1 & 85 & 17 & 3 & 51 & 8 & 94 & 45 & 33 & 105 \\
\hline $\begin{array}{c}\text { Case 2 } \\
\text { (Employee) }\end{array}$ & 21 & 72 & 80 & 27 & 105 & 17 & 15 & 85 & 54 & 3 & 43 & 8 & 1 & 94 & 45 & $104 *$ & $6^{*}$ & 4 & 33 & 108 \\
\hline $\begin{array}{c}\text { Case } 3 \\
\text { (Employee) }\end{array}$ & 72 & 21 & 80 & 27 & $17^{*}$ & $105^{*}$ & 15 & 8 & $54^{*}$ & $85^{*}$ & 6 & 43 & 46 & 3 & $51^{*}$ & $33^{*}$ & 1 & 40 & 45 & 94 \\
\hline $\begin{array}{c}\text { Case } 4 \\
\text { (Employee) }\end{array}$ & 21 & 80 & 72 & 27 & 85 & 6 & $17 *$ & $105^{*}$ & 54 & 1 & 15 & 43 & 3 & 94 & 46 & 8 & 45 & 51 & 40 & 108 \\
\hline $\begin{array}{c}\text { Case } 5 \\
\text { (Employee) }\end{array}$ & 21 & 72 & 80 & 27 & 15 & 54 & 3 & 1 & $43^{*}$ & $6^{*}$ & 85 & $17 *$ & $105^{*}$ & 94 & 8 & $45^{*}$ & $4^{*}$ & 33 & 104 & 40 \\
\hline $\begin{array}{c}\text { Case } 6 \\
\text { (Employee) }\end{array}$ & 21 & $27^{*}$ & $72 *$ & 6 & 80 & 17 & 40 & 54 & 43 & 3 & 85 & 1 & 8 & 46 & 108 & 105 & 15 & 51 & 45 & 94 \\
\hline
\end{tabular}

\section{Conclusion}

This study can be used as a starting point to implement systems thinking skills as a supplemental recruiting tool. The purpose of this research is to use systems thinking skills as an organization's selection tool, along with the existing recruiting methods when hiring prospective employees with various systems thinking skills. These skills are important to identify, especially with the increasing complexity and uncertainty surrounding work environments. The identifications of these skills will allow the right positioning and recruitment of individuals that will fit the skills levels requirements of the job. Thus, enhance work performance. In an attempt to close this gap, this research introduces a new expert system tool to expert HRM professionals to help them classify employees based on the systems thinking skills. Since recruitment is a decision-making process, this tool implements MDCM methods to help classify employees based on their systems thinking skills.

The aim of the study is to rank all prospective employees based on the systems thinking skills they possess and then to classify the most appropriate candidates commensurate with the organization's strategy. Based on the literature, two important strategies are identified for ranking prospective applicants: 1) Job Fit Recruiting where applicants are ranked according to the systems thinking skills needed for the organizational environment and 2) Flexible Recruiting where applicants are ranked according to the highest systems thinking skills they possess. To implement these two strategies, we used two MCDM methods-- $L_{p}$ metric for the Job Fit Recruiting strategy and ELECTRE III for the Flexible Recruiting strategy to rank the pool of prospective employees and to select the most eligible ones among them corresponding to the organization's strategy. Fuzzy logic and a group decision-making approach are used to identify the weights for each systems thinking dimension. A real case study of a large-scale US-based organization, including two strategies, was used to validate the proposed approach. 


\subsection{Potential Implications of the Study}

This research sets the basis for new recruiting tools that can mimic the decision-making aptitude of expert recruiters to match employers' needs. Besides individuals' systems skills, the proposed framework can be expanded to include personality traits, level of problem-solving ability, resource management capacity, content, and social skills.

The proposed framework can be related to the expert systems' state of the art in regard to 1) smart recruitment system in the basis of systems thinking skills, 2) knowledge-based intelligent system to predict future workforce need of the organization based on employers' opinion, 3) continuous assessment of workforce's soft skills level, 4) recommender system to suggest some on-the-job-training, workshop, and others to improve employees' systemic skills, and 5) measure the effectiveness of the training.

Some other potential implications of the proposed framework can be categorized as follow:

- The proposed framework can be used to assess the level of systems thinking skills of current employees of an organization (instead of using it as a recruiting tool). The intent is to evaluate current employees within departments or other segments in the organization such as middle managers, engineering department, etc. According to the seven systems thinking skills they possess, the proposed system can suggest some on the job training, workshops, and seminars to enhance these skills in the current employees. The implications of this study is consistent with a study called, "Future of Jobs survey" where 65 percent of respondents (e.g., strategic leaders and upper management of top 100 companies in each industry) from nine major industries (e.g., basic and infrastructure, energy, healthcare, etc.) emphasize on investing in reskilling current employees outpacing other strategies such as support mobility and job rotation, collaborate, educational institutions, target female talent, attract foreign talent, offer apprenticeships, among others (World Economic Forum, 2016).

- For a better comprehensive and smart screening system, the proposed framework can be designed for other screening criteria such as personality traits, level of problem-solving ability, resource management capacity, content, and social skills. This system would assist HRM experts in the comprehensive evaluation of the current workforce or prospective employees, which is consistent with industry 4.0 direction (World Economic Forum, 2016).

- Since the job environment in organizations is dynamic and changing, the level of complexity demand of the work environment should be updated periodically based on the opinion of expert HRM professionals. The proposed framework can work as a recommender system to assist more accurate decision making for future HRM purposes. For example, if the level of complexity demand reported by HRM professionals drastically changed over time due to the complexity of projects, the proposed framework 
can update the gap analysis report suggesting the mismatch between the workforce's level of systems thinking and the environmental complexity level. This approach can work as a "continuous improvement" strategy to maintain an up-to-date workforce for the organization.

Although the proposed framework presents promising results and provides new ideas and future perspectives concerning recruitment methods, it also comes with some limitations. First, the employees might select certain answers on the self-report survey to show themselves to be more qualified for the position than they really are. Second, the demographics of the data set have not considered throughout the analysis. An investigation of the distribution of demographics may provide a better picture when ranking candidates. Third, the candidates' skills are aggregated using a fuzzy preference relation. Other approaches might be investigated in future research. Fourth, ELECTRE III has limitations regarding its compensatory method, independence concerning inappropriate actions, or the possible and frequent occurrence of intransitivity (Figueira, Greco, Roy, \& Słowiński, 2010).

There are many different MCDM methods that could be implemented in the current study. Other studies could use samples from various industries and occupations. The results of future studies could be compared with the results of this study to show the reliability of the methods used. A post-hoc analysis of employed candidates could be conducted to make sure the research achieved its purpose (validity phase). To overcome the disadvantages of using traditional survey designs, future research can utilize scenario-based virtual reality modules to retrieve the measures of individuals' systems thinking skills (Ma et al., 2019). Then the researchers can use more accurate measures to feed into the decision making systems to recruit better candidates. 


\section{References}

Ahmad, S., \& Schroeder, R. G. (2002). The importance of recruitment and selection process for sustainability of total quality management. International Journal of Quality and Reliability Management, 19(5), 540550.

Alias, M. A., Hashim, S. Z. M., \& Samsudin, S. (2008). Multi-criteria decision making and its applications: a literature review. Jurnal Teknologi Maklumat, 20(2), 129-152.

Ravindran, A. R. (2016). Multiple criteria decision making in supply chain management (pp. 35-38). CRC Press.

Aruldoss, M., Lakshmi, T. M., \& Venkatesan, V. P. (2013). A survey on multi-criteria decision-making methods and its applications. American Journal of Information Systems, 1(1), 31-43.

Assari, A., \& Assari, E. (2012). Role of public participation in the sustainability of historical city: usage of TOPSIS method. Indian Journal of Science and Technology, 5(3), 2289-2294.

Atwater, J. B., Kannan, V. R., \& Stephens, A. A. (2008). Cultivating systemic thinking in the next generation of business leaders. Academy of Management Learning and Education, 7(1), 9-25.

Boardman, J., \& Sauser, B. (2006). The system of Systems-the meaning of. In System of Systems Engineering, 2006 IEEE/SMC International Conference on (pp. 6-pp). IEEE.

Beardwell, J., \& Wright, M. (2002). Recruitment and selection. In I. Beardwell and L. Holden (Eds.), Human resource management: A contemporary approach (pp. 189-229). Harlow, England: Prentice Hall.

Camelia, F., \& Ferris, T. L. (2016). Undergraduate students' engagement with systems thinking: results of a survey study. IEEE Transactions on Systems, Man, and Cybernetics: Systems, 47(12), 3165-3176.

Cole, G. (2002). Personnel and human resource management. London: Continuum.

Checkland, P. (1999). Systems Thinking, Systems Practice, John Wiley and Sons, New York.

Celotto, A., Loia, V., \& Senatore, S. (2015). Fuzzy linguistic approach to quality assessment model for electricity network infrastructure. Information Sciences, 304, 1-15.

Chen, S. J., \& Hwang, C. L. (1992). Fuzzy multiple attribute decision making methods. In Fuzzy multiple attribute decision making (pp. 289-486). Springer, Berlin, Heidelberg.

Dahling, J. J., \& Librizzi, U. A. (2015). Integrating the theory of work adjustment and attachment theory to predict job turnover intentions. Journal of Career Development, 42(3), 215-228.

DeLaurentis, D. (2005). Understanding transportation as a system-of-systems design problem. In 43rd AIAA Aerospace Sciences Meeting and Exhibit (p. 123).

Delery, J., \& Shaw, J. (2001). The strategic management of people in work organizations: Review, synthesis, and extension. In G. Ferris (Ed.), Research in personnel and human resource management (pp. 16597). New York: JAI.

Deza, M. M., \& Deza, E. (2009). Encyclopedia of distances. In Encyclopedia of Distances (pp. 1-583). Springer, Berlin, Heidelberg.

Dolansky, M. A., \& Moore, S. M. (2013). Quality and safety education for nurses (QSEN): The key is systems thinking. Online Journal of Issues in Nursing, 18(3), 1-12.

Dutta, P., Boruah, H., \& Ali, T. (2011). Fuzzy Arithmetic with and without using $\alpha$-cut method: A Comparative Study. International Journal of Latest Trends in Computing, 2(1), 99-107.

Figueira, J. R., Greco, S., \& Matthias E. (2005). Multiple Criteria Decision Analysis: State of the Art Surveys. New York: Springer Science + Business Media, Inc. ISBN 0-387-23081-5.

Figueira, J. R., Greco, S., Roy, B., \& Słowiński, R. (2010). ELECTRE methods: main features and recent developments. In Handbook of multicriteria analysis (pp. 51-89). Springer, Berlin, Heidelberg.

Frank, M. (2002), "What is "engineering systems thinking”?", Kybernetes, Vol. 31 No. 9/10, pp. 1350-1360. https://doi.org/10.1108/03684920210443554

Frank, M. (2010). Assessing the interest for systems engineering positions and other engineering positions' required capacity for engineering systems thinking (CEST). Systems Engineering, 13(2), 161-174.

Gamage, A. S. (2014). Recruitment and selection practices in manufacturing SMEs in Japan: An analysis of the link with business performance. Ruhuna Journal of Management and Finance, 1(1), 37-52. 
Gerstein, M. \& Reisman, H. (1983) Strategic selection: Matching executives to business conditions. Sloan Management Review, 24(2), 1-18.

Giannoulis, C., \& Ishizaka, A. (2010). A Web-based decision support system with ELECTRE III for a personalised ranking of British universities. Decision Support Systems, 48(3), 488-497.

Gorod, A., Sauser, B., \& Boardman, J. (2008). System-of-systems engineering management: A review of modern history and a path forward. IEEE Systems Journal, 2(4), 484-499.

Gupta, A. K. (1984). Contingency linkages between strategy and general manager characteristics: A conceptual examination. Academy of Management Review, 9(3), 399-412.

Hambrick, D. C., \& Mason, P. A. (1984). Upper echelons: The organization as a reflection of its top managers. Academy of management review, 9(2), 193-206.

Hesketh, B. (1993). Toward a better adjusted theory of work adjustment. Journal of Vocational Behavior, 43(1), 75-83.

Hoffman, B. J., \& Woehr, D. J. (2006). A quantitative review of the relationship between personorganization fit and behavioral outcomes. Journal of vocational behavior, 68(3), 389-399.

Hopper, M., \& Stave, K. A. (2008, July). Assessing the effectiveness of systems thinking interventions in the classroom. In 26th International Conference of the System Dynamics Society.

Hossain, N. U. I., Jaradat, R. M., Hamilton, M. A., Keating, C. B., \& Goerger, S. R. (2020). A historical perspective on development of systems engineering discipline: a review and analysis. Journal of Systems Science and Systems Engineering, 29(1), 1-35.

Hunter, J. E., Schmidt, F. L., \& Judiesch, M. K. (1990). Individual differences in output variability as a function of job complexity. Journal of Applied Psychology, 75(1), 28.

Hwang, C. L., \& Yoon, K. (1981). Multi-objective decision making-methods and application. A state-ofthe-art study.

Jaradat, R. M. (2015). Complex system governance requires systems thinking-how to find systems thinkers. International Journal of System of Systems Engineering, 6(1-2), 53-70.

Jaradat, R. M., \& Keating, C. B. (2016). Systems thinking capacity: implications and challenges for complex system governance development. International Journal of System of Systems Engineering, 7(1-3), 7594.

Jaradat, R. M., Keating, C. B., \& Bradley, J. M. (2018). Individual capacity and organizational competency for systems thinking. IEEE Systems Journal, 12(2), 1203-1210.

Jaradat, R., Stirgus, E., Goerger, S. R., Buchanan, R. K., Ibne Hossain, N. U., Ma, J., \& Burch, R. (2019). Assessment of Workforce Systems Preferences/Skills Based on Employment Domain. Engineering Management Journal, 1-13.

Keating, C. B. (2008). Emergence in the system of systems. System of systems engineering: Innovations for the 21st century, 169-190.

Kerr, J. (1982). Assigning managers on the basis of the life cycle. Journal of Business Strategy, 2(4), 58-65.

Kerr, J. L., \& Jackofsky, E. F. (1989). Aligning managers with strategies: Management development versus selection. Strategic Management Journal, 10(S1), 157-170.

Liu, B., Liu, J., \& Hu, J. (2010). Person-organization fit, job satisfaction, and turnover intention: An empirical study in the Chinese public sector. Social Behavior and Personality: an international journal, 38(5), 615-625.

Liu, H. C., Ren, M. L., Wu, J., \& Lin, Q. L. (2013). An interval 2-tuple linguistic MCDM method for robot evaluation and selection. International Journal of Production Research, 52(10), 2867-2880.

Leisink, P., \& Steijn, B. (2009). Public service motivation and job performance of public sector employees in the Netherlands. International Review of Administrative Sciences, 75(1), 35-52.

Lengnick-Hall, C. A., \& Lengnick-Hall, M. L. (1988). Strategic human resources management: A review of the literature and a proposed typology. Academy of Management Review, 13(3), 454-470.

Ma, J., Jaradat, R., Ashour, O., Hamilton, M., Jones, P., \& Dayarathna, V. L. (2019). Efficacy investigation of virtual reality teaching module in manufacturing system design course. Journal of Mechanical Design, 141(1). 
Ma, J., \& Kremer, G. E. O. (2015). “A Fuzzy Logic-Based Approach to Determine Product Component EOL Option from the Combination of Sustainability and Designer's Perception," Journal of Cleaner Production (DOI: 10.1016/j.jclepro.2015.08.029).

Ma, J., \& Kremer, G. E. O. (2016). "A Sustainable Modular Product Design Approach with Key Components and Uncertain EOL Options Consideration," International Journal of Advanced Manufacturing Technology (DOI: 10.1007/s00170-015-7979-0).

Ma, J., Kremer, G.E.O., \& Ray, C.D. (2018). A Comprehensive End-of-Life Strategy Decision Making Approach to Handle Uncertainty in the Product Design Stage, Research in Engineering Design, 29 (3), 469-487.

Merino, D., \& Farr, J. (Ed.) (2010). The engineering management handbook (1st ed.). Rolla, MO: The American Society of Engineering Management.

Milliman, J., Glinow, M. A. V., \& Nathan, M. (1991). Organizational life cycles and strategic international human resource management in multinational companies: Implications for congruence theory. Academy of management review, 16(2), 318-339.

Nagahi, M., Jaradat, R. Goerger, S., Hamilton, M., Buchanan, R., Abutabenjeh, S. \& Ma, J. (2020a). The Impact of Practitioners' Personality Types on Their Level of Systems-Thinking Skills Preferences. Engineering Management journal, (In Press).

Nagahi, M., El Amrani, S., Jaradat, R., Hamilton, M. \& Goerger S. R. (2020b). Holistic and Reductionist Thinkers: A Comparison Study Based on Individuals' Skillset and Personality Types. Int. Journal of System of Systems Engineering, (In Press).

Olian, J. D., \& Rynes, S. L. (1984). Organizational staffing: Integrating practice with strategy. Industrial Relations, 23(2), 170.

Olszewski, D. H. (2014). The use of systems thinking by the industrial engineer as an organizational leader (Doctoral dissertation, Walsh College).

Plate, R. (2008). Attracting institutional support through better assessment of systems thinking. Creative Learning Exchange Newsletter, 17(3), 1-8.

Richmond, B. (2000). The" thinking" in systems thinking: Seven essential skills. Pegasus Communications.

Roy, B. (1968). Classement et choix en présence de points de vue multiples. Revue française d'informatique et de recherche opérationnelle, 2(8), 57-75.

Roy, B. (1990). The outranking approach and the foundations of ELECTRE methods. In Readings in multiple criteria decision aid (pp. 155-183). Springer, Berlin, Heidelberg.

Rynes, S. L., \& Barber, A. E. (1990). Applicant attraction strategies: An organizational perspective. Academy of Management Review, 15(2), 286-310.

Saaty, T. L. (1977). A scaling method for priorities in hierarchical structures. Journal of mathematical psychology, 15(3), 234-281.

Saaty, T. L. (1990). How to make a decision: the analytic hierarchy process. European journal of operational research, 48(1), 9-26.

Saaty, T. L. (2008). Decision making with the analytic hierarchy process. International journal of services sciences, 1(1), 83-98.

Saaty, T. L. (2013). Analytic hierarchy process. In Encyclopedia of operations research and management science (pp. 52-64). Springer, Boston, MA.

Salgado, J. F., Viswesvaran, C., \& Ones, D. S. (2001). Predictors used for personnel selection: An overview of constructs. Handbook of industrial, word and organizational psychology, 165-199.

Schiuma, G., Carlucci, D., \& Sole, F. (2012). Applying a systems thinking framework to assess knowledge assets dynamics for business performance improvement. Expert Systems with Applications, 39(9), 80448050 .

Schneider, B. (1987). The people make the place. Personnel Psychology, 40(3), 437-453.

Schneider, B., Goldstiein, H. W., \& Smith, D. B. (1995). The ASA framework: An update. Personnel psychology, 48(4), 747-773.

Singh, A., \& Malik, S. K. (2014). Major MCDM Techniques and their application-A Review. IOSR Journal of Engineering (IOSRJEN), ISSN (e): 2250-3021, ISSN (p): 2278-8719 Vol, 4. 
Snell, A., Youndt, A., \& Wright, M. (1996). Establishing a framework for research in strategic human resource management: Merging resource theory and organizational learning, Research in Personnel and Human Resources Management, 14.

Snow, C. C., \& Snell, S. A. (1993). Staffing as strategy. Personnel selection in organizations, 4, 448-478.

Triantaphyllou, E. (2000). Multi-criteria decision making methods. In Multi-criteria decision making methods: A comparative study (pp. 5-21). Springer, Boston, MA.

Wiecek, M. M., Ehrgott, M., Fadel, G., \& Figueira, J. R. (2008). Multiple criteria decision making for engineering. Omega: The International Journal of Management Science, 36(3), 337-339.

World Economic Forum. (2016, January). The future of jobs: Employment, skills and workforce strategy for the fourth industrial revolution. In Global Challenge Insight Report, World Economic Forum, Geneva.

Wright, P. M., \& Snell, S. A. (1998). Toward a unifying framework for exploring fit and flexibility in strategic human resource management. Academy of management review, 23(4), 756-772.

Yang, S. L., \& Li, T. F. (2002). Agility evaluation of mass customization product manufacturing. Journal of Materials Processing Technology, 129(1-3), 640-644.

Ye, Y., Jankovic, M., \& Kremer, G. E. (2015). Understanding the impact of subjective uncertainty on architecture and supplier identification in early complex systems design. ASCE-ASME Journal of Risk and Uncertainty in Engineering Systems, Part B: Mechanical Engineering, 1(3), 031005.

Zadeh, L. A. (1965). Fuzzy sets. Information \& control, 8(3), 338-353.

Zadeh, L. A. (1975a). The concept of a linguistic variable and its application to approximate reasoningI. Information sciences, 8(3), 199-249.

Zadeh, L. A. (1975b). The concept of a linguistic variable and its application to approximate reasoningII. Information sciences, 8(4), 301-357.

Zadeh, L. A. (1975c). The concept of a linguistic variable and its application to approximate reasoningIII. Information sciences, $9(1), 43-80$. 


\section{Appendix A}

\begin{tabular}{|c|c|c|c|c|c|c|c|}
\hline & Complexity & Autonomy & Interaction & Change & Uncertainty & Hierarchical View & Flexibility \\
\hline Employee 1 & 83.3 & 40 & 83.3 & 50 & 66.7 & 20 & 100 \\
\hline Employee 2 & 50 & 20 & 50 & 33.3 & 33.3 & 20 & 80 \\
\hline Employee 3 & 83.3 & 40 & 66.7 & 66.7 & 33.3 & 40 & 100 \\
\hline Employee 4 & 83.3 & 80 & 66.7 & 33.3 & 33.3 & 20 & 100 \\
\hline Employee 5 & 33.3 & 40 & 66.7 & 50 & 50 & 40 & 60 \\
\hline Employee 6 & 83.3 & 100 & 83.3 & 50 & 66.7 & 40 & 80 \\
\hline Employee 7 & 50 & 60 & 33.3 & 66.7 & 0 & 20 & 40 \\
\hline Employee 8 & 33.3 & 80 & 50 & 50 & 50 & 100 & 100 \\
\hline Employee 9 & 66.7 & 20 & 33.3 & 33.3 & 33.3 & 20 & 100 \\
\hline Employee 10 & 16.7 & 80 & 66.7 & 33.3 & 33.3 & 40 & 60 \\
\hline Employee 11 & 33.3 & 20 & 33.3 & 33.3 & 33.3 & 40 & 80 \\
\hline Employee 12 & 33.3 & 20 & 50 & 33.3 & 16.7 & 20 & 80 \\
\hline Employee 13 & 66.7 & 60 & 100 & 33.3 & 33.3 & 0 & 80 \\
\hline Employee 14 & 66.7 & 40 & 66.7 & 33.3 & 33.3 & 0 & 100 \\
\hline Employee 15 & 66.7 & 80 & 83.3 & 33.3 & 33.3 & 60 & 100 \\
\hline Employee 16 & 50 & 40 & 33.3 & 33.3 & 50 & 20 & 80 \\
\hline Employee 17 & 66.7 & 40 & 50 & 50 & 66.7 & 80 & 100 \\
\hline Employee 18 & 50 & 40 & 66.7 & 50 & 33.3 & 0 & 100 \\
\hline Employee 19 & 50 & 20 & 66.7 & 33.3 & 50 & 20 & 100 \\
\hline Employee 20 & 66.7 & 60 & 66.7 & 50 & 16.7 & 20 & 80 \\
\hline Employee 21 & 66.7 & 100 & 66.7 & 66.7 & 66.7 & 60 & 100 \\
\hline Employee 22 & 33.3 & 40 & 50 & 100 & 50 & 0 & 100 \\
\hline Employee 23 & 83.3 & 80 & 83.3 & 33.3 & 33.3 & 60 & 60 \\
\hline Employee 24 & 50 & 80 & 50 & 50 & 66.7 & 20 & 80 \\
\hline Employee 25 & 66.7 & 60 & 50 & 33.3 & 33.3 & 0 & 100 \\
\hline Employee 26 & 66.7 & 60 & 50 & 66.7 & 50 & 20 & 60 \\
\hline Employee 27 & 83.3 & 60 & 83.3 & 50 & 50 & 60 & 100 \\
\hline Employee 28 & 66.7 & 20 & 66.7 & 33.3 & 16.7 & 40 & 80 \\
\hline Employee 29 & 33.3 & 20 & 16.7 & 33.3 & 50 & 40 & 40 \\
\hline Employee 30 & 83.3 & 80 & 66.7 & 83.3 & 16.7 & 20 & 60 \\
\hline Employee 31 & 33.3 & 60 & 83.3 & 33.3 & 33.3 & 20 & 80 \\
\hline Employee 32 & 83.3 & 60 & 83.3 & 16.7 & 50 & 60 & 80 \\
\hline Employee 33 & 50 & 100 & 100 & 33.3 & 33.3 & 60 & 80 \\
\hline Employee 34 & 16.7 & 80 & 66.7 & 16.7 & 16.7 & 20 & 60 \\
\hline Employee 35 & 16.7 & 60 & 33.3 & 66.7 & 16.7 & 0 & 60 \\
\hline Employee 36 & 50 & 40 & 33.3 & 50 & 16.7 & 20 & 60 \\
\hline Employee 37 & 66.7 & 40 & 66.7 & 50 & 50 & 20 & 80 \\
\hline Employee 38 & 83.3 & 80 & 33.3 & 50 & 16.7 & 60 & 100 \\
\hline Employee 39 & 16.7 & 20 & 66.7 & 50 & 33.3 & 60 & 80 \\
\hline
\end{tabular}




\begin{tabular}{|c|c|c|c|c|c|c|c|}
\hline & Complexity & Autonomy & Interaction & Change & Uncertainty & Hierarchical View & Flexibility \\
\hline Employee 40 & 66.7 & 40 & 100 & 66.7 & 50 & 40 & 80 \\
\hline Employee 41 & 100 & 60 & 66.7 & 16.7 & 33.3 & 40 & 100 \\
\hline Employee 42 & 66.7 & 80 & 66.7 & 50 & 0 & 20 & 60 \\
\hline Employee 43 & 66.7 & 80 & 83.3 & 66.7 & 33.3 & 20 & 100 \\
\hline Employee 44 & 33.3 & 40 & 33.3 & 50 & 33.3 & 20 & 40 \\
\hline Employee 45 & 66.7 & 60 & 83.3 & 33.3 & 66.7 & 20 & 100 \\
\hline Employee 46 & 33.3 & 100 & 66.7 & 50 & 50 & 100 & 80 \\
\hline Employee 47 & 50 & 60 & 50 & 33.3 & 50 & 40 & 80 \\
\hline Employee 48 & 50 & 20 & 50 & 50 & 33.3 & 20 & 100 \\
\hline Employee 49 & 50 & 20 & 50 & 33.3 & 50 & 0 & 40 \\
\hline Employee 50 & 33.3 & 60 & 50 & 50 & 33.3 & 0 & 80 \\
\hline Employee 51 & 66.7 & 40 & 83.3 & 50 & 50 & 80 & 80 \\
\hline Employee 52 & 50 & 40 & 16.7 & 50 & 50 & 40 & 60 \\
\hline Employee 53 & 33.3 & 40 & 50 & 50 & 16.7 & 20 & 60 \\
\hline Employee 54 & 83.3 & 60 & 66.7 & 66.7 & 33.3 & 40 & 100 \\
\hline Employee 55 & 33.3 & 60 & 66.7 & 33.3 & 66.7 & 20 & 60 \\
\hline Employee 56 & 50 & 40 & 50 & 50 & 50 & 20 & 60 \\
\hline Employee 57 & 100 & 20 & 66.7 & 50 & 50 & 0 & 100 \\
\hline Employee 58 & 50 & 60 & 66.7 & 50 & 16.7 & 60 & 60 \\
\hline Employee 59 & 33.3 & 40 & 33.3 & 33.3 & 16.7 & 20 & 60 \\
\hline Employee 60 & 83.3 & 80 & 66.7 & 50 & 16.7 & 0 & 80 \\
\hline Employee 61 & 83.3 & 80 & 66.7 & 50 & 16.7 & 60 & 60 \\
\hline Employee 62 & 33.3 & 60 & 33.3 & 16.7 & 50 & 0 & 80 \\
\hline Employee 63 & 50 & 40 & 83.3 & 33.3 & 33.3 & 20 & 80 \\
\hline Employee 64 & 50 & 20 & 33.3 & 66.7 & 0 & 20 & 80 \\
\hline Employee 65 & 33.3 & 20 & 50 & 33.3 & 33.3 & 0 & 100 \\
\hline Employee 66 & 66.7 & 20 & 50 & 50 & 16.7 & 40 & 80 \\
\hline Employee 67 & 100 & 80 & 33.3 & 33.3 & 33.3 & 40 & 100 \\
\hline Employee 68 & 16.7 & 60 & 50 & 50 & 33.3 & 60 & 80 \\
\hline Employee 69 & 66.7 & 20 & 33.3 & 50 & 33.3 & 0 & 80 \\
\hline Employee 70 & 50 & 60 & 16.7 & 50 & 50 & 0 & 80 \\
\hline Employee 71 & 66.7 & 20 & 66.7 & 50 & 33.3 & 20 & 80 \\
\hline Employee 72 & 100 & 80 & 66.7 & 50 & 33.3 & 100 & 100 \\
\hline Employee 73 & 16.7 & 20 & 66.7 & 33.3 & 33.3 & 0 & 80 \\
\hline Employee 74 & 83.3 & 100 & 83.3 & 33.3 & 33.3 & 100 & 60 \\
\hline Employee 75 & 33.3 & 40 & 50 & 33.3 & 50 & 20 & 80 \\
\hline Employee 76 & 50 & 40 & 66.7 & 50 & 16.7 & 20 & 80 \\
\hline Employee 77 & 50 & 20 & 33.3 & 66.7 & 33.3 & 40 & 100 \\
\hline Employee 78 & 33.3 & 40 & 33.3 & 33.3 & 33.3 & 20 & 80 \\
\hline Employee 79 & 50 & 40 & 50 & 33.3 & 33.3 & 60 & 100 \\
\hline
\end{tabular}




\begin{tabular}{|c|c|c|c|c|c|c|c|}
\hline & Complexity & Autonomy & Interaction & Change & Uncertainty & Hierarchical View & Flexibility \\
\hline Employee 80 & 83.3 & 80 & 83.3 & 33.3 & 50 & 80 & 100 \\
\hline Employee 81 & 50 & 40 & 83.3 & 50 & 16.7 & 80 & 80 \\
\hline Employee 82 & 16.7 & 20 & 50 & 33.3 & 50 & 20 & 100 \\
\hline Employee 83 & 50 & 20 & 50 & 66.7 & 50 & 40 & 100 \\
\hline Employee 84 & 33.3 & 40 & 83.3 & 66.7 & 33.3 & 20 & 80 \\
\hline Employee 85 & 66.7 & 40 & 83.3 & 33.3 & 66.7 & 60 & 100 \\
\hline Employee 86 & 66.7 & 80 & 83.3 & 33.3 & 33.3 & 40 & 60 \\
\hline Employee 87 & 50 & 20 & 66.7 & 66.7 & 33.3 & 40 & 80 \\
\hline Employee 88 & 33.3 & 80 & 50 & 50 & 16.7 & 20 & 60 \\
\hline Employee 89 & 33.3 & 40 & 66.7 & 66.7 & 33.3 & 40 & 80 \\
\hline Employee 90 & 83.3 & 40 & 66.7 & 33.3 & 50 & 0 & 80 \\
\hline Employee 91 & 66.7 & 80 & 50 & 16.7 & 50 & 60 & 80 \\
\hline Employee 92 & 50 & 40 & 33.3 & 33.3 & 33.3 & 0 & 80 \\
\hline Employee 93 & 50 & 40 & 66.7 & 50 & 33.3 & 20 & 60 \\
\hline Employee 94 & 83.3 & 40 & 83.3 & 50 & 50 & 20 & 100 \\
\hline Employee 95 & 33.3 & 20 & 50 & 50 & 16.7 & 20 & 100 \\
\hline Employee 96 & 33.3 & 40 & 50 & 33.3 & 33.3 & 40 & 80 \\
\hline Employee 97 & 50 & 40 & 50 & 50 & 50 & 60 & 60 \\
\hline Employee 98 & 50 & 40 & 50 & 50 & 16.7 & 20 & 80 \\
\hline Employee 99 & 33.3 & 60 & 50 & 50 & 50 & 20 & 40 \\
\hline Employee 100 & 66.7 & 60 & 66.7 & 50 & 16.7 & 0 & 60 \\
\hline Employee 101 & 66.7 & 60 & 33.3 & 16.7 & 16.7 & 20 & 80 \\
\hline Employee 102 & 33.3 & 40 & 50 & 33.3 & 16.7 & 0 & 80 \\
\hline Employee 103 & 33.3 & 60 & 66.7 & 50 & 50 & 20 & 80 \\
\hline Employee 104 & 66.7 & 80 & 66.7 & 33.3 & 50 & 20 & 100 \\
\hline Employee 105 & 66.7 & 40 & 66.7 & 33.3 & 66.7 & 80 & 100 \\
\hline Employee 106 & 83.3 & 20 & 50 & 50 & 33.3 & 40 & 100 \\
\hline Employee 107 & 50 & 40 & 50 & 66.7 & 50 & 20 & 60 \\
\hline Employee 108 & 66.7 & 60 & 50 & 50 & 66.7 & 20 & 100 \\
\hline
\end{tabular}




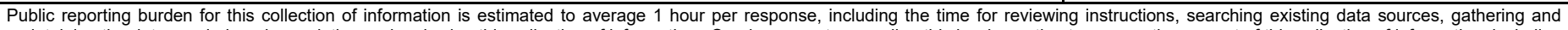

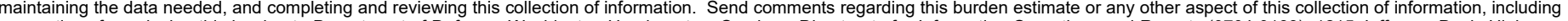

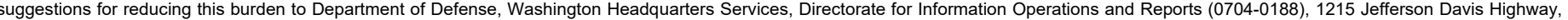

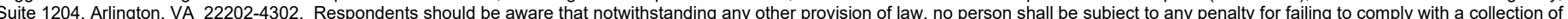

information if it does not display a currently valid OMB control number. PLEASE DO NOT RETURN YOUR FORM TO THE ABOVE ADDRESS.

\begin{tabular}{l|l}
$\begin{array}{l}\text { 1. REPORT DATE (DD-MM-YYYY) } \\
\text { June } 2021\end{array}$ & $\begin{array}{c}\text { 2. REPORT TYPE } \\
\text { Final }\end{array}$ \\
\hline 4. TITLE AND SUBTITLE & \\
& \\
& \\
Integrating Systems Thinking Skills with Multi-Criteria Decision-Making \\
Technology to Recruit Employee Candidates
\end{tabular}

Technology to Recruit Employee Candidates

3. DATES COVERED (From - To)

5a. CONTRACT NUMBER

5b. GRANT NUMBER

5c. PROGRAM ELEMENT NUMBER

$0603461 \mathrm{~A}$

6. AUTHOR(S)

5d. PROJECT NUMBER

DW5

Sofia Karam, Morteza Nagahi, Vidanelage L. Dayarathna (Nick), Junfeng Ma,

Raed Jaradat, and Michael Hamilton

5e. TASK NUMBER

01

5f. WORK UNIT NUMBER

\section{PERFORMING ORGANIZATION NAME(S) AND ADDRESS(ES)}

U.S. Army Engineer Research and Development Center

8. PERFORMING ORGANIZATION REPORT NUMBER

Information Technology Laboratory

3909 Halls Ferry Road

ERDC/ITL MP-21-11

Vicksburg, MS 39180

9. SPONSORING / MONITORING AGENCY NAME(S) AND ADDRESS(ES)

10. SPONSOR/MONITOR'S ACRONYM(S)

See next page.

11. SPONSOR/MONITOR'S REPORT NUMBER(S)

\section{DISTRIBUTION / AVAILABILITY STATEMENT}

Approved for public release; distribution is unlimited.

\section{SUPPLEMENTARY NOTES}

Originally published online in Expert Systems with Applications on 30 May 2020.

\section{ABSTRACT}

The emergence of modern complex systems is often exacerbated by a proliferation of information and complication of technologies. Because current complex systems challenges can limit an organization's ability to efficiently handle socio-technical systems, it is essential to provide methods and techniques that count on individuals' systems skills. When selecting future employees, companies must constantly refresh their recruitment methods in order to find capable candidates with the required level of systemic skills who are better fit for their organization's requirements and objectives. The purpose of this study is to use systems thinking skills as a supplemental selection tool when recruiting prospective employees. To the best of our knowledge, there is no prior research that studied the use of systems thinking skills for recruiting purposes. The proposed framework offers an established tool to HRM professionals for assessing and screening of prospective employees of an organization based on their level of systems thinking skills while controlling uncertainties of complex decision-making environment with the fuzzy linguistic approach. This framework works as an expert system to find the most appropriate candidate for the organization to enhance the human capital for the organization.

\section{SUBJECT TERMS}

Recruitment strategy, Systems thinking skills, Job-fit recruiting, Flexible recruiting, lp Metric, ELECTRE III

\section{SECURITY CLASSIFICATION OF:}

\section{a. REPORT}

Unclassified

\section{b. ABSTRACT}

Unclassified

\section{c. THIS PAGE}

Unclassified
17. LIMITATION OF ABSTRACT

SAR
18. NUMBER OF PAGES

42 19a. NAME OF RESPONSIBLE PERSON 19b. TELEPHONE NUMBER (include area code) 
7. PERFORMING ORGANIZATION NAME(S) AND ADDRESS(ES)

U.S. Army Engineer Research and Development Center Information Technology Laboratory

3909 Halls Ferry Road

Vicksburg, MS 39180

Department of Industrial and Systems Engineering Mississippi State University

Starkville, MS 39762

Institute for Systems Engineering

Mississippi State University

Starkville, MS 39762 